\title{
Community structure and function of high-temperature chlorophototrophic microbial mats inhabiting diverse geothermal environments
}

\author{
Christian G. Klatt ${ }^{1,2}+$, William P. Inskeep ${ }^{1,2}{ }^{*}$, Markus J. Herrgard ${ }^{3}$, Zackary J. Jay ${ }^{1,2}$, Douglas B. Rusch $^{4}$, \\ Susannah G. Tringe ${ }^{5}$, M. Niki Parenteau ${ }^{6,7}$, David M. Ward ${ }^{1,2}$, Sarah M. Boomer ${ }^{8}$, Donald A. Bryant ${ }^{9,10}$ and \\ Scott R. Miller ${ }^{11}$
}

${ }^{1}$ Department of Land Resources and Environmental Sciences, Montana State University, Bozeman, MT, USA

${ }^{2}$ Thermal Biology Institute, Montana State University, Bozeman, MT, USA

${ }^{3}$ Novo Nordisk Foundation Center for Biosustainability, Technical University of Denmark. Hørsholm, Denmark

${ }^{4}$ Center for Genomics and Bioinformatics, Indiana University, Bloomington, IN, USA

${ }^{5}$ Department of Energy Joint Genome Institute, Walnut Creek, CA, USA

${ }^{6}$ Search for Extraterrestrial Intelligence Institute, Mountain View, CA, USA

${ }^{7}$ National Aeronautics and Space Administration Ames Research Center, Mountain View, CA, USA

${ }^{8}$ Western Oregon University, Monmouth, OR, USA

${ }^{9}$ Department of Biochemistry and Molecular Biology, The Pennsylvania State University, University Park, PA, USA

${ }^{10}$ Department of Chemistry and Biochemistry, Montana State University, Bozeman, MT, USA

"Department of Biological Sciences, University of Montana, Missoula, MT, USA

Edited by: Carolina at Charlotte, USA

\section{Reviewed by:}

Andreas Teske, University of North

Carolina at Chapel Hill, USA

Jesse Dillon, California State

University, USA

\section{*Correspondence:}

William P. Inskeep, Land Resources and Environmental Sciences,

Montana State University, Bozeman,

MT 59717, USA

e-mail: binskeep@montana.edu

\section{${ }^{\dagger}$ Present address:}

Christian G. Klatt, Department of

Swedish University of Agricultural

Sciences, Umeå, Sweden.
Martin G. Klotz, University of North

Forest Ecology and Management,

Six phototrophic microbial mat communities from different geothermal springs (YNP) were studied using metagenome sequencing and geochemical analyses. The primary goals of this work were to determine differences in community composition of high-temperature phototrophic mats distributed across the Yellowstone geothermal ecosystem, and to identify metabolic attributes of predominant organisms present in these communities that may correlate with environmental attributes important in niche differentiation. Random shotgun metagenome sequences from six phototrophic communities (average $\sim 53 \mathrm{Mbp} / \mathrm{site}$ ) were subjected to multiple taxonomic, phylogenetic, and functional analyses. All methods, including $\mathrm{G}+\mathrm{C}$ content distribution, MEGAN analyses, and oligonucleotide frequencybased clustering, provided strong support for the dominant community members present in each site. Cyanobacteria were only observed in non-sulfidic sites; de novo assemblies were obtained for Synechococcus-like populations at Chocolate Pots (CP_7) and Fischerella-like populations at White Creek (WC_6). Chloroflexi-like sequences (esp. Roseiflexus and/or Chloroflexus spp.) were observed in all six samples and contained genes involved in bacteriochlorophyll biosynthesis and the 3-hydroxypropionate carbon fixation pathway. Other major sequence assemblies were obtained for a Chlorobiales population from CP_7 (proposed family Thermochlorobacteriaceae), and an anoxygenic, sulfur-oxidizing Thermochromatium-like (Gamma-proteobacteria) population from Bath Lake Vista Annex (BLVA_20). Additional sequence coverage is necessary to establish more complete assemblies of other novel bacteria in these sites (e.g., Bacteroidetes and Firmicutes); however, current assemblies suggested that several of these organisms play important roles in heterotrophic and fermentative metabolisms. Definitive linkages were established between several of the dominant phylotypes present in these habitats and important functional processes such as photosynthesis, carbon fixation, sulfur oxidation, and fermentation.

Keywords: microbial mats, microbial interactions, phototrophic bacteria, functional genomics, thermophilic bacteria

\section{INTRODUCTION}

Many naturally occurring microorganisms have eluded isolation, due in part to a poor understanding of the chemical, physical, and biotic factors defining their realized niches (Rappé and Giovannoni, 2003). Moreover, much of the sequence diversity revealed by amplification of specific gene targets (e.g., $16 \mathrm{~S}$ rRNA) is susceptible to biases inherent in primer-design and PCR protocols.
Random shotgun sequencing of environmental DNA provides a direct and potentially less biased view of the composition and functional attributes of microbial communities. For example, three new chlorophototrophic organisms (i.e., organisms capable of (bacterio)chlorophyll-based phototrophy) were discovered in prior metagenome analyses of oxygenic mats in YNP, two of which lie outside the clades of known phototrophic organisms 
in the Chlorobiales and Chloroflexi (Klatt et al., 2011). Moreover, the third organism, "Candidatus Chloracidobacterium thermophilum" ("Ca. C. thermophilum"), represents the only known occurrence of chlorophototrophy in the phylum Acidobacteria (Bryant et al., 2007; Klatt et al., 2011; Garcia Costas et al., 2012). Metagenome sequencing and subsequent bioinformatic analyses provide an opportunity to identify the metabolic attributes of uncultivated organisms that can be used to postulate detailed biochemical linkages among individual community members necessary for the development of computational models describing microbial interaction and community function (Taffs et al., 2009).

High-temperature phototrophic microbial mats have served as models for studying microbial community structure and function. Studies have included investigations of microbial community composition (Miller et al., 2009), the ecophysiology of novel isolates (Pierson and Castenholz, 1974; Bryant et al., 2007; van der Meer et al., 2010), comparative genomics, metagenomics, and metatranscriptomics (Bhaya et al., 2007; Klatt et al., 2007, 2011; Becraft et al., 2011; Liu et al., 2011, 2012; Melendrez et al., 2011), community network modeling (Taffs et al., 2009), phage-host interactions (Heidelberg et al., 2009), as well as theoretical models of evolution (Ward et al., 2008). The high temperature and relative geochemical stability of geothermal phototrophic mats in YNP generally result in communities with several dominant phylotypes and have provided opportunities for understanding environmental factors controlling community composition (Brock, 1978; Cohen and Rosenberg, 1989; Ward and Castenholz, 2000; Ward et al., 2012). Prior investigations have revealed that temperature, $\mathrm{pH}$, and sulfide are among the most important environmental variables dictating differences in phototrophic mat community structure (Castenholz, 1976, 1977; Castenholz and Pierson, 1995; Madigan et al., 2005; Cox et al., 2011; Boyd et al., 2012). The presence of sulfide was used in the current study to separate anoxygenic versus oxygenic communities common in YNP (Inskeep et al., 2013). Oxygenic and/or anoxygenic photoautotrophs are generally the predominant primary producers in geothermal mats at temperatures of $\sim 50-72^{\circ} \mathrm{C}$ and moderately acidic to alkaline $\mathrm{pH}$ (5-9). These mat communities support a diverse array of (photo-) heterotrophic, fermentative, sulfate-respiring, and methanogenic organisms, whose physiological attributes are critical for understanding community function (Zeikus and Wolfe, 1972; Jackson et al., 1973; Henry et al., 1994; Nold and Ward, 1996; Ward et al., 1998; Taffs et al., 2009; Klatt et al., 2011; Liu et al., 2012).

The distribution of different chlorophototrophic bacteria is often controlled by specific geochemical parameters. For example, members of the Cyanobacteria are not generally found in acidic or sulfidic environments (Castenholz, 1976, 1977). However, filamentous anoxygenic phototrophs (FAPs) of the phylum Chloroflexi exhibit a wider habitat range than other chlorophototrophs. Closely related members of the Chloroflexi [ $>97 \%$ nucleotide identity (NT ID) of the 16S rRNA gene] with different phenotypes have been cultured from geothermal environments (Madigan et al., 1974; Madigan and Brock, 1975). FAPs isolated from a high-sulfide $(>100 \mu \mathrm{M})$ spring in the absence of cyanobacteria (Chloroflexus sp. GCF strains) fixed inorganic carbon using sulfide as the electron donor (Giovannoni et al., 1987). However, most other cultured Chloroflexus spp. from low-sulfide environments are photoheterotrophic and do not utilize reduced sulfur for photosynthesis (Madigan et al., 1974; Pierson and Castenholz, 1974). Natural populations of FAPs are known to consume organic compounds produced by cyanobacterial community members (van der Meer et al., 2005); however, genomic and biochemical evidence is needed to improve our understanding of how different populations of Chloroflexi function in situ.

The overall goal of this study was to investigate the underlying environmental factors and potential physiological adaptations important in defining the microbial community structure and function of different types of chlorophototrophic mats commonly found in association with certain geothermal features of YNP (Inskeep et al., 2013). The specific objectives of this study were to (i) utilize metagenome sequencing and bioinformatic analyses to determine the community composition of thermal chlorophototrophic mats in YNP, (ii) identify key metabolic attributes of the major chlorophototrophic organisms present in these communities, and (iii) evaluate the predominant environmental and/or geochemical attributes that contribute to niche differentiation of thermophilic chlorophototrophic communities. The habitats sampled in the current study were chosen to focus on several of the major high-temperature phototrophic mat types that are distributed across the YNP geothermal ecosystem.

\section{RESULTS \\ GEOCHEMICAL AND PHYSICAL CONTEXT}

The predominant differences among the six phototrophic microbial mat communities included both geochemical characteristics such as $\mathrm{pH}$ and dissolved sulfide (DS), as well as temperature, and the sample depth (Figure 1; Table 1). Temperature ranged from $40-60^{\circ} \mathrm{C}$ across these six sites, and is a critical parameter controlling community composition. Four of the geothermal sites contained no measurable DS, while both samples from Bath Lake Vista Annex Spring (BLVA_5 and BLVA_20) were collected from hypoxic sulfidic environments (total DS $\sim 117 \mu \mathrm{M})$. Although the dissolved oxygen content at the source of Chocolate Pots (near sample location CP_7) was below detection $(<1 \mu \mathrm{M})$, this spring contained no sulfide and high concentrations of $\mathrm{Fe}$ (II) $(\sim 76 \mu \mathrm{M})$ (Table 1), which results in the precipitation of $\mathrm{Fe}$ (III)-oxides upon discharge and reaction with oxygen (Trouwborst et al., 2007). The phototrophic mat obtained from White Creek (WC_6) occurs within an oxygenated, alkaline-siliceous geothermal drainage channel containing no detectable DS (Table 1). The site was included in the study to target a population of the heterocyst-forming cyanobacterium Fischerella (Mastigocladus) laminosus that has been the focus of prior work at this location (Miller et al., 2006, 2007, 2009).

Samples from Mushroom Spring (MS_15) and Fairy Geyser (FG_16) were obtained from laminated phototrophic mats after removal of the top layer (See Materials and Methods). Dissection of these mats was performed to focus on FAPs, which were known to occur in higher abundance at greater depths below a surface layer dominated by cyanobacteria (Boomer et al., 2002; Nübel et al., 2002). The phototrophic mats at FG_16 are referred to as "splash-mats" due to the fact that these communities receive frequent inputs of geothermal water emanating from the main source 


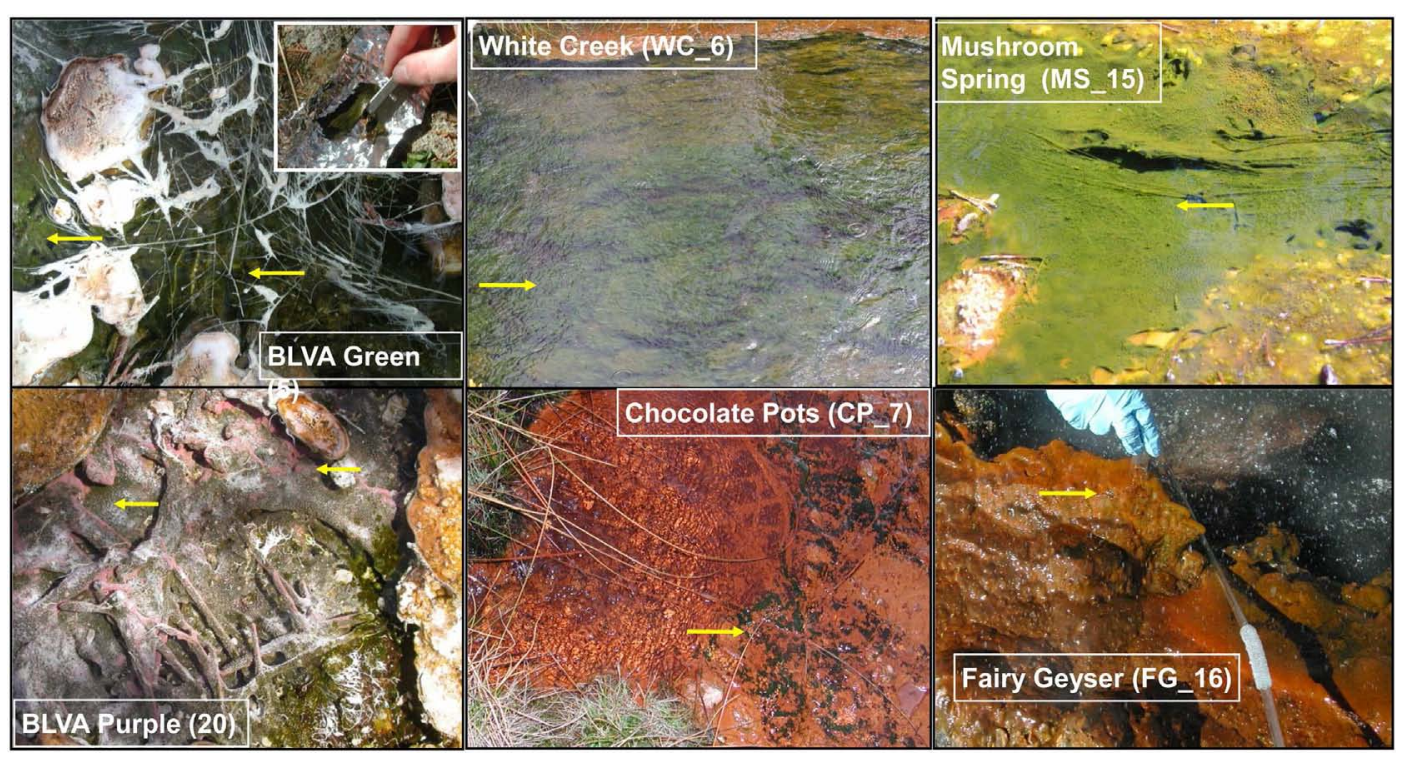

FIGURE 1 | Site photographs of phototrophic microbial mats selected for metagenome sequencing. The sites cover a range in geochemical conditions including (i) highly sulfidic environments at Bath Lake Vista Annex (BLVA_5, 20), (ii) oxygenic phototrophic communities at White Creek (WC_6) and Chocolate Pots (CP_7), and (iii) subsurface mat layers at Mushroom Spring (MS_15) and Fairy Geyser (FG_16) (also oxygenic systems). The anoxygenic phototrophic communities at Bath Lake Vista Annex (BLVA) were sampled at two different time points (Table S2 in Inskeep et al., 2013) to compare Chloroflexus mats in the absence (BLVA_5) and presence (BLVA_20) of purple-bacteria (Arrows indicate approximate sample locations and types; inset at BLVA_5 shows mat dissection at sampling).

Table 1 | Sample locations and aqueous geochemical parameters ${ }^{1}$ of six, high-temperature phototrophic microbial communities sampled in Yellowstone National Park (YNP) and used for metagenome sequencing.

\begin{tabular}{|c|c|c|c|c|c|c|c|c|c|c|c|c|c|}
\hline \multirow[t]{2}{*}{ Location } & \multirow[t]{2}{*}{$\mathbf{T}\left({ }^{\circ} \mathrm{C}\right)$} & \multirow[t]{2}{*}{$\mathbf{p H}$} & \multirow[t]{2}{*}{$\mathrm{Na}^{+}$} & $\mathrm{Cl}^{-}$ & $\mathrm{SO}_{4}^{2-}$ & ${ }^{1} \mathrm{DIC}$ & ${ }^{1} \mathrm{DS}$ & ${ }^{1} \mathrm{DO}$ & ${ }^{1} \mathrm{DOC}$ & As & ${ }^{2} \mathrm{Fe}$ & ${ }^{3} \mathrm{NH}_{4}^{+}$ & \multirow[t]{2}{*}{ Coordinates } \\
\hline & & & & \multicolumn{3}{|c|}{$\mathbf{m M}$} & \multicolumn{6}{|c|}{$\mu \mathbf{M}$} & \\
\hline \multirow{2}{*}{$\begin{array}{l}\text { Bath Lake Vista } \\
\text { Annex-Green (BVLA_5) }\end{array}$} & 57 & 6.2 & 3.9 & 4.4 & 5.6 & 15.8 & 117 & $<3$ & 104 & 24 & 0.7 & 40 & $44^{\circ} 57^{\prime} 54.180^{\prime \prime} \mathrm{N}$ \\
\hline & & & & & & & & & & & & & $110^{\circ} 42^{\prime} 42.228^{\prime \prime} \mathrm{W}$ \\
\hline \multirow{2}{*}{$\begin{array}{l}\text { Bath Lake Vista } \\
\text { Annex-Purple (BLVA_20) }\end{array}$} & 54 & 6.2 & 5.5 & 5.7 & 7.3 & 24.2 & 117 & $<3$ & 75 & 23 & 0.7 & 40 & $44^{\circ} 57^{\prime} 54.180^{\prime \prime} \mathrm{N}$ \\
\hline & & & & & & & & & & & & & $110^{\circ} 42^{\prime} 42.228^{\prime \prime} \mathrm{W}$ \\
\hline \multirow[t]{2}{*}{ White Creek (WC_6) } & 52 & 8.2 & 3.6 & 1.8 & 0.23 & nd & $<3$ & 188 & nd & 5 & 1.7 & 1.9 & $44^{\circ} 31^{\prime} 53.399^{\prime \prime} \mathrm{N}$ \\
\hline & & & & & & & & & & & & & $110^{\circ} 47^{\prime} 51.799^{\prime \prime} \mathrm{W}$ \\
\hline \multirow[t]{2}{*}{ Chocolate Pots (CP_7) } & 52 & 6.2 & 4.1 & 0.89 & 0.23 & 13.2 & $<3$ & $<3$ & 38 & 9 & 75.5 & 4.2 & $44^{\circ} 42^{\prime} 36.288^{\prime \prime} \mathrm{N}$ \\
\hline & & & & & & & & & & & & & $110^{\circ} 44^{\prime} 28.824^{\prime \prime} \mathrm{W}$ \\
\hline \multirow{2}{*}{$\begin{array}{l}\text { Mushroom Spring } \\
\text { (MS_15) }\end{array}$} & 60 & 8.2 & 12.6 & 7.3 & 0.18 & 2.1 & $<3$ & 141 & nd & 26 & $<1$ & 4.4 & $44^{\circ} 32^{\prime} 19.284^{\prime \prime} \mathrm{N}$ \\
\hline & & & & & & & & & & & & & $110^{\circ} 47^{\prime} 52.692^{\prime \prime} \mathrm{W}$ \\
\hline \multirow[t]{2}{*}{ Fairy Geyser (FG_16) } & $36-38$ & 9.1 & 9.4 & 5.2 & 0.18 & 4.8 & $<3$ & 31 & 30 & 13 & $<1$ & 1.3 & $44^{\circ} 32^{\prime} 31.812^{\prime \prime} \mathrm{N}$ \\
\hline & & & & & & & & & & & & & $110^{\circ} 51^{\prime} 40.788^{\prime \prime} \mathrm{W}$ \\
\hline \multicolumn{2}{|l|}{${ }^{4}$ Correlation $\left(r^{2}\right)$} & $0.89^{*}$ & & $0.93^{*}$ & $0.96^{*}$ & & $0.99^{* * *}$ & & & & $0.72^{* *}$ & $0.99^{* *}$ & \\
\hline
\end{tabular}

${ }^{1} D S$, total dissolved sulfide; DO, dissolved oxygen; DIC, dissolved inorganic carbon; DOC, dissolved organic carbon.

${ }^{2} \mathrm{Mn}$ (total soluble) values were also significant in $\mathrm{CP}_{-} 7(24 \mu \mathrm{M})$ and WC_6 $(5 \mu \mathrm{M})$, but low in other sites $(0.1-0.2 \mu \mathrm{M}$, or below detection of $0.1 \mu \mathrm{M})$.

${ }^{3}$ Nitrate values ranged from $2.1-6.7 \mu \mathrm{M}$ across sites.

${ }^{4}$ Correlation significance values: ${ }^{*} p<0.05,{ }^{*} p<0.01,{ }^{* * *} p<0.001$.

pool $\left(85-88^{\circ} \mathrm{C}\right)$ (Figure 1). The "splash-mats" surrounding FG_16 are reasonably thick $(\sim 3-5 \mathrm{~cm})$, and the sample discussed here was collected from a $2-4 \mathrm{~mm}$ "red-layer," found within a temperature range of $35-50^{\circ} \mathrm{C}$ and a $\mathrm{pH}$ approaching 9 (Boomer et al., 2000, 2002). The visual characteristic of the "red-layer" was apparent during sampling and represents a different subsurface 
environment than the sample obtained from MS_15. No measurable DS was present in the bulk aqueous phase (Table 1) of these mats; however, subsurface mats in these systems (MS_15 and FG_16) have been shown to be less oxic than their respective near-surface layers (Jensen et al., 2011).

\section{ANALYSIS OF METAGENOME SEQUENCES}

Individual sequences (average length $\sim 800 \mathrm{bp}$ ) were analyzed using several complementary approaches including alignmentbased comparisons to reference databases, and evaluation of the guanine and cytosine content $(\% \mathrm{G}+\mathrm{C})$ of each sequence read. In addition, comparison of all sequences to the NCBI nr database (blastx) was accomplished using MEGAN (Huson et al., 2007). The most highly represented phyla across all sites included the Chloroflexi $(28 \%)$, Cyanobacteria (12\%), Proteobacteria (8\%), Bacteroidetes (6\%), and Chlorobi (2\%). Many sequence reads (27\%) did not match those available in NCBI ("no hits"); this indicated that some members of these communities are not represented in current databases.

Taxonomic assignment of individual sequences was combined with $\% \mathrm{G}+\mathrm{C}$ distribution to obtain a profile of community composition (Figure 2). Each site contained populations similar to Chloroflexus and/or Roseiflexus spp., with average $\mathrm{G}+\mathrm{C}$ contents of 55 and $61 \%$, respectively. The two sulfidic samples (BLVA_5 and BLVA_20) showed contributions from both Chloroflexus and Roseiflexus-like populations (Figure 2). The oxic community from White Creek (WC_6) also contained significant contributions from Chloroflexus-like organisms, while CP_7, MS_15 and FG_16 were enriched in Roseiflexus-like sequences (Figure 2). All sites contain a significant number of sequences contributed from novel Chloroflexi that have not been adequately characterized, and for which appropriate reference organisms have not yet been cultivated or sequenced.

The phototrophic mat communities from WC_6 and CP_7 contained a significant fraction of sequences $(23$ and $25 \%$, respectively) contributed from members of the Cyanobacteria. Both sites contained sequences related to Synechococcus spp. strains $\mathrm{A}$ and $\mathrm{B}^{\prime}$ (mean $\mathrm{G}+\mathrm{C}$ content of $60 \%$; Bhaya et al., 2007) (Figure 2; Figure A1 in Appendix), but the WC_6 community yielded a large proportion of Cyanobacteria-like sequences $(73 \%)$ that could not be classified beyond the phylum-level, and these sequences exhibit a large range in $\mathrm{G}+\mathrm{C}$ content $(40-65 \%)$. Fisherella laminosus (order Stigonematales) has been shown to be an important community member at WC_6 (Miller et al., 2009), and many of the cyanobacterial sequences from WC_6 showed high sequence identity (95\% average NT ID of alignments) to the draft genome of Fischerella sp. JSC-11 (average $\mathrm{G}+\mathrm{C}=41 \%$; Figure A2 in Appendix), which was the only representative genome available for this group of cyanobacteria (at time of writing). The $\mathrm{G}+\mathrm{C}$ content frequency plots also revealed major contributions from organisms within the Chlorobi (at sites CP_7 and FG_16), Thermotoga (MS_15), and Thermochromatium spp. (purple-sulfur bacteria) in BLVA_20 with an average $\mathrm{G}+\mathrm{C}$ content of $64 \%$. Moreover, all sites contained bacterial sequences that could not be identified beyond the level of Domain Bacteria (especially G $+\mathrm{C}$ contents ranging from $20-40 \%$, Figure 2), in part because appropriate reference genomes are not currently available, and significant assemblies were not obtained for phylotypes present in lower abundance.

\section{ANALYSIS OF METAGENOME ASSEMBLIES}

The assembly of individual sequence reads into contigs and scaffolds is a powerful method for linking functional attributes with specific phylotypes. Assembly yielded scaffolds ranging from $1 \mathrm{~kb}$ (small contigs) to nearly $126 \mathrm{~kb}$ (largest scaffold), and an average scaffold size of $2,330 \mathrm{bp}$ across all six sites. Community structure plays a role in the degree of assembly and the ability to obtain large scaffolds; communities with larger proportions of metagenome sequence originating from fewer, more dominant

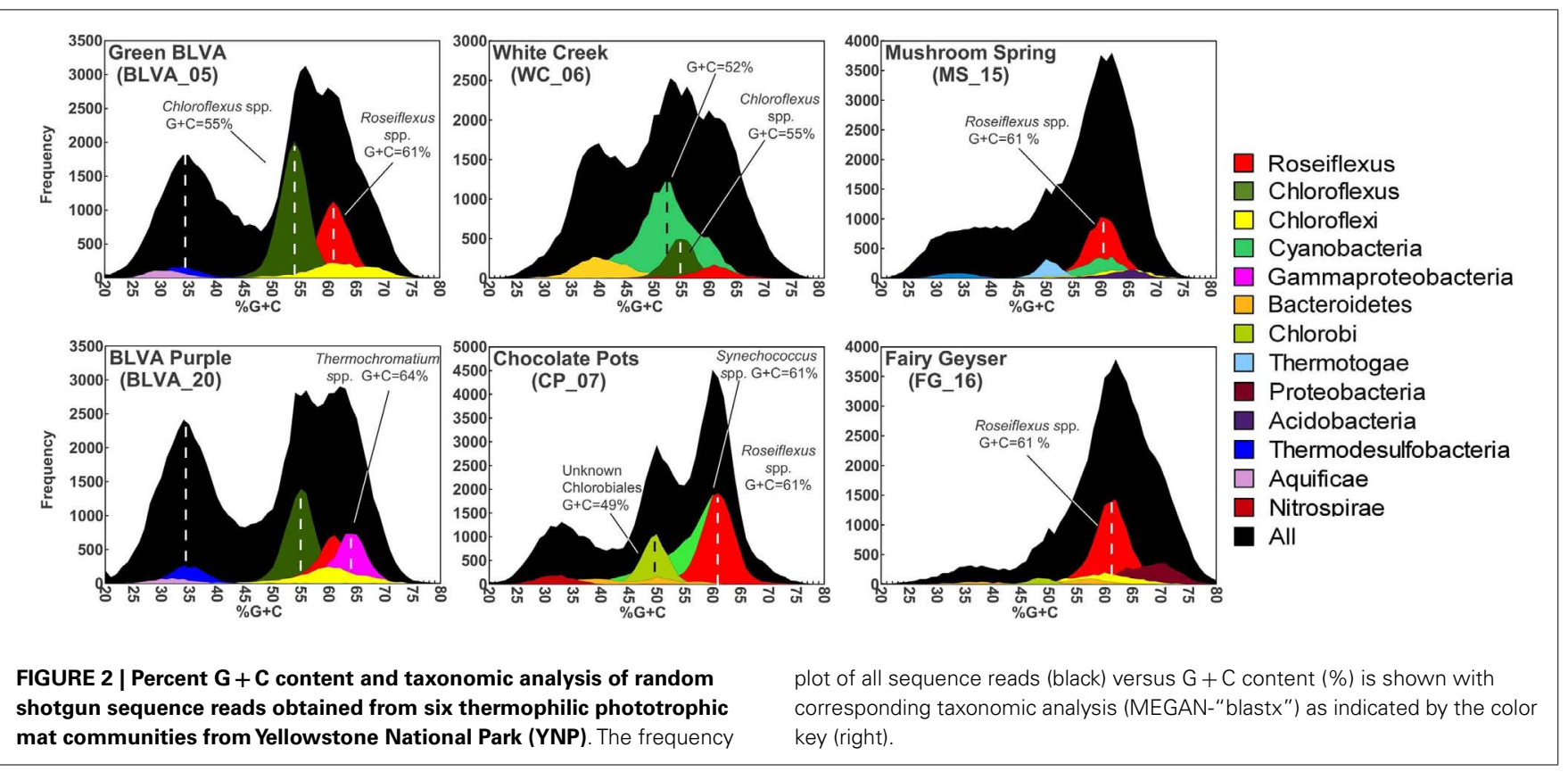




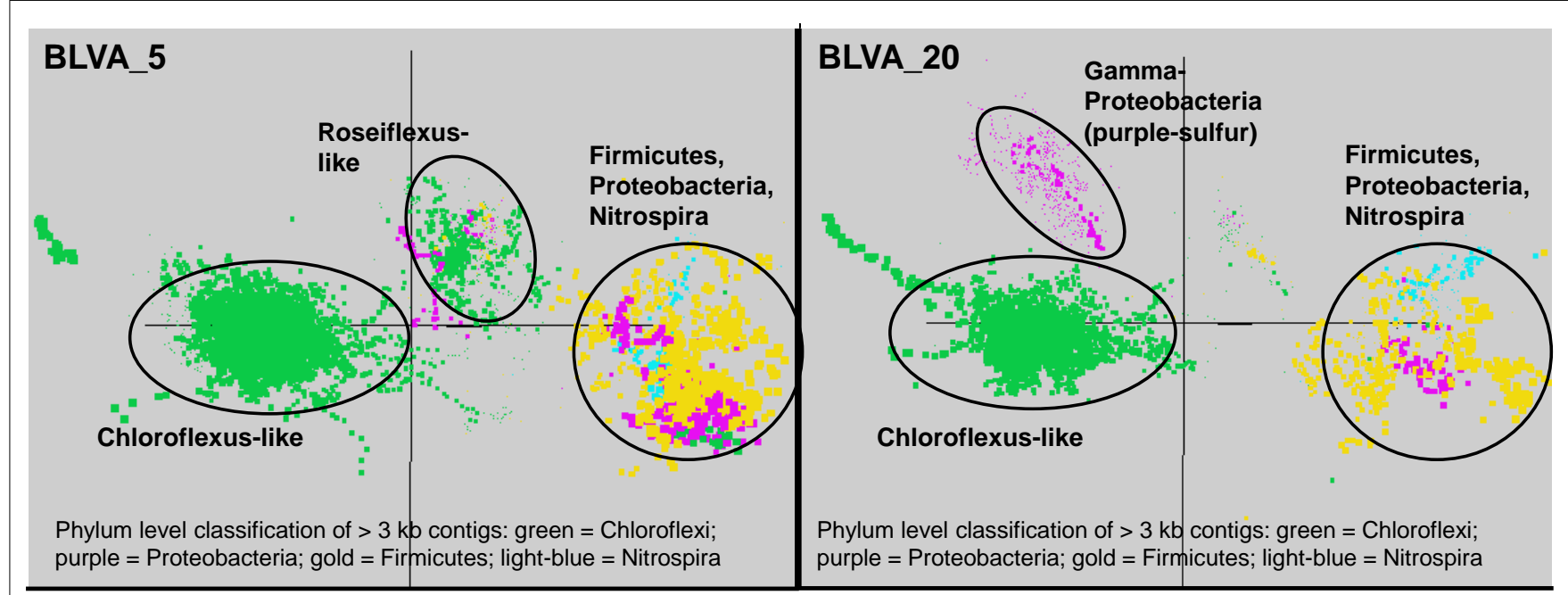

FIGURE 3 | Principal components analysis of oligonucleotide frequencies of assembled sequence from Bath Lake Vista Annex. BLVA_20 was sampled 8 months after BLVA_5 to capture a bloom of purple-sulfur bacteria shown in prior work to be related to Thermochromatium tepidum (Castenholz, 1977; Ward et al., 1989). Both sites contained scaffolds from dominant populations of Chloroflexus spp., Firmicutes, Nitrospira, and additional proteobacteria, but only BLVA_20 contained numerous scaffolds corresponding to the population of purple-sulfur bacteria

(Gamma-proteobacteria, family Chromatiaceae, average $\mathrm{G}+\mathrm{C} \sim 64 \%$ ) that is notably absent in BLVA_5. organisms resulted in longer assemblies. Diversity metrics of PCRbased 16S rRNA sequences that were produced simultaneously from the same samples indicated that subsurface mat communities from MS_15 and FG_16 exhibited higher Simpson's diversity values (reported as the reciprocal of the Simpson's index, $\lambda^{-1}$; Table A1 in Appendix). The greater degree of species "evenness" in MS_15 and FG_16 yielded considerably smaller assemblies, and only two scaffolds $>10 \mathrm{~kb}$ were obtained from each of these two sites. Contrastingly, CP_7 exhibited the lowest Simpson's $\lambda^{-1}$, and the largest assemblies were obtained from this site, which contributed $42 \%$ of the large scaffolds $(>10 \mathrm{~kb}$ ) obtained across all six sites. Large assemblies were also obtained from the anoxygenic mats at BLVA (BLVA_5,_20), and these samples had similarly low values for Simpson's $\lambda^{-1}$.

\section{NUCLEOTIDE WORD-FREOUENCY ANALYSIS OF DOMINANT POPULATIONS}

Sequence assemblies were examined using principal components analysis (PCA) of nucleotide word frequencies (NWF) (Teeling et al., 2004) in conjunction with a taxonomic classification algorithm of average scaffold identity (APIS; Badger et al., 2006). For example, NWF PCA plots of the sulfidic system at BLVA sampled 8 months apart revealed major differences in community composition associated with a visible bloom of purple-sulfur bacteria in BLVA_20 (Figures 1 and 3). The major change in community composition between the two samples was the Thermochromatium-like population in BLVA_20, which corresponded with a decrease in Roseiflexus-like sequences (Figure 3). Both BLVA samples revealed a dominant Chloroflexus-like population that corresponded to the $\mathrm{G}+\mathrm{C}$ peak at 55\% (Figure 2). Similar NWF PCA analyses of assemblies from $\mathrm{CP}_{-} 7$ revealed three predominant community members related to Roseiflexus, Synechococcus, and "Candidatus Thermochlorobacter aerophilum"-like organisms (“Ca. T. aerophilum" represents a novel clade in the order Chlorobiales; Liu et al., 2012). Several other organisms were present in lower abundance and were distantly related to members of the Firmicutes, Bacteroidetes, and Spirochetes (Figure A3 in Appendix). The large Chlorobi-like assemblies obtained from $\mathrm{CP} \_7$ were phylogenetically related (average NT ID $=91 \%$ ) to “ $C a$. T. aerophilum" assemblies obtained from Mushroom and Octopus Springs metagenomes (Klatt et al., 2011; Liu et al., 2012). Translated PscD sequences from this newly described lineage of uncultivated Chlorobi are clearly distinct from other previously described phototrophic Chlorobi (PscD sequences from the CP_7 and Mushroom populations have 95\% amino acid identity (AA ID) (Figure A4 in Appendix).

A Monte-Carlo approach was also used to compare normalized oligonucleotide frequencies across the six phototrophic sites, which clustered the scaffolds of highly related organisms (e.g., genus/species level). A minimum scaffold length of $10 \mathrm{kbp}$ was used to focus the analysis on dominant assemblies; consequently, smaller scaffolds from subsurface mat communities (MS_15 and FG_16) were not well represented in this analysis. Twelve scaffold clusters (consensus k-means groupings) were observed across sites (Figure 4; Table 2), and each of these populations corresponded with dominant community members identified using $\mathrm{G}+\mathrm{C}$ content $(\%)$ and BLASTP assignments (Figure 2; Figure A5 in Appendix). Clustering by oligonucleotide frequency afforded greater discrimination among populations that exhibited similar G + C content. For example, Roseiflexus-like organisms have similar G + C content (61\%) to Synechococcus sp. strains A and B' (Figure 2), yet these different genera are clearly separated based on differences in sequence character using oligonucleotide clustering analysis (Figure 4).

A sequence cluster corresponding to Thermochromatium spp. (Gamma-proteobacteria) contained sequences solely from 


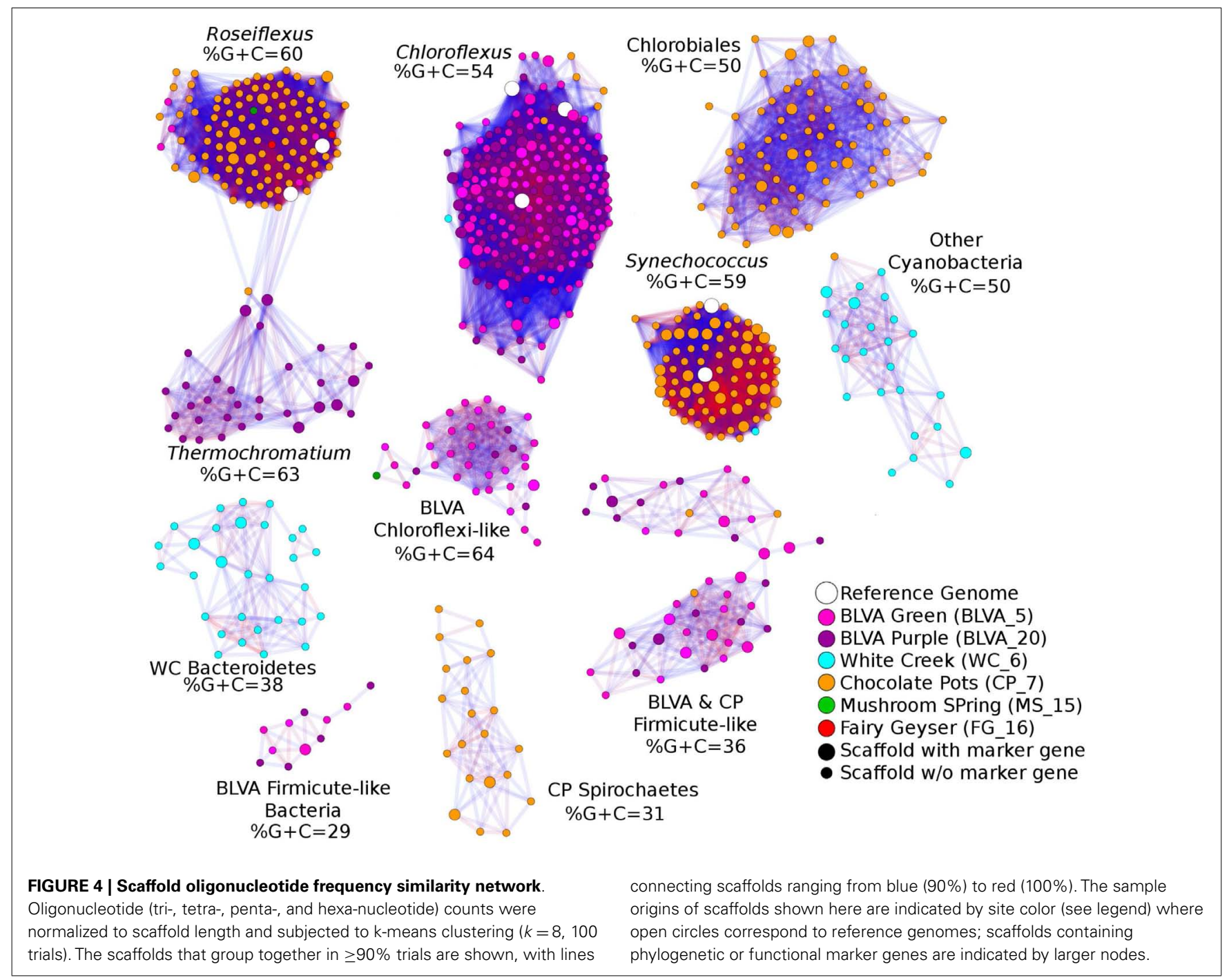

Table 2 | Properties of scaffold clusters obtained from metagenome assemblies as demarcated with oligonucleotide composition and confirmed using phylogenetic analyses.

\begin{tabular}{|c|c|c|c|c|c|c|c|}
\hline $\begin{array}{l}\text { Scaffold } \\
\text { cluster }\end{array}$ & Taxonomic affiliation & Sites & $\begin{array}{l}\text { No. of } \\
\text { scaffolds }\end{array}$ & $\begin{array}{l}\text { Median size } \\
\text { (kbase) }\end{array}$ & $\begin{array}{l}\text { G+C } \\
(\%) \pm \text { SD }\end{array}$ & $\begin{array}{l}\text { Total sequence } \\
\text { (Mbase) }\end{array}$ & $\begin{array}{l}\text { Depth of } \\
\text { coverage (x) }\end{array}$ \\
\hline 1 & Roseiflexus spp. & BLVA_5, CP_7, MS_15, FG_16 & 112 & 12.5 & $60.0 \pm 1.2$ & 1.55 & $2.6 \pm 0.4$ \\
\hline 3 & Ca. Thermochlorobacter spp. & CP_7 & 73 & 14.8 & $49.5 \pm 0.8$ & 1.13 & $2.7 \pm 0.5$ \\
\hline 4 & Thermochromatium spp. & BLVA_20 & 29 & 12.5 & $63.0 \pm 1.3$ & 0.37 & $2.1 \pm 0.4$ \\
\hline 5 & Synechococcus spp. & WC_6, CP_7 & 78 & 26.2 & $58.7 \pm 1.1$ & 2.59 & $4.0 \pm 0.7$ \\
\hline 7 & Bacteroidetes & WC_6 & 30 & 11.1 & $37.7 \pm 0.9$ & 0.37 & $2.4 \pm 0.4$ \\
\hline 8 & Chloroflexi-like & BLVA_5, MS_15, BLVA_20 & 37 & 10.6 & $63.9 \pm 2.3$ & 0.44 & $2.5 \pm 0.5$ \\
\hline 9 & Firmicute-like & BLVA_5, CP_7, BLVA_20 & 47 & 14.2 & $36.0 \pm 1.5$ & 0.79 & $2.7 \pm 0.4$ \\
\hline 10 & Firmicute-like & BVLA_5, BLVA_20 & 11 & 12.7 & $29.0 \pm 1.4$ & 0.16 & $2.6 \pm 0.6$ \\
\hline 11 & Spirochaetes & $\mathrm{CP}_{-} 7$ & 21 & 11.8 & $30.5 \pm 1.4$ & 0.25 & $2.3 \pm 0.4$ \\
\hline
\end{tabular}

Scaffold clusters 7-11 represent novel bacteria that are not well represented in public databases, and are currently defined at the phylum level. 
BLVA_20, which is consistent with visual evidence of this population at the time of sampling (Figure 1), as well as further NWF PCA analysis using contigs $>20 \mathrm{~kb}$ (Figure A6 in Appendix). Other major sequence clusters identified included the " $\mathrm{Ca}$. T. aerophilum"-like population from $\mathrm{CP}_{-} 7$ (discussed above). Although relatives of the Bacteroidetes were found to occupy all sites, larger assemblies of several of these community members were obtained from WC_6. Three scaffold clusters with comparatively low $\mathrm{G}+\mathrm{C}$ content $(<40 \%)$ were observed, but neither AMPHORA (based on phylogenetic analysis) nor MEGAN ("blastx" alignments) could classify the sequences in these groups. This suggested that they originated from organisms that are currently poorly represented in public databases.

\section{USE OF SINGLE-COPY GENES TO DEMARCATE DOMINANT POPULATIONS}

Phylogenetically informative single-copy genes were identified among the metagenome assemblies using AMPHORA (Wu and
Eisen, 2008), and provided yet another method for evaluating the predominant taxa represented in the six metagenomes. The distribution of dominant phylotypes predicted using AMPHORA (Figure 5A) was similar to that observed using the combined "blastx" and G+C (\%) analyses of individual sequences (Figure 2), as well as to the taxonomic distribution of PCR-based 16S rRNA gene libraries from these same sites (Figure 5B). Moreover, the distribution of predominant populations (e.g., Chloroflexi, Cyanobacteria, Chlorobi, Proteobacteria) across sites was consistent with detailed analysis of major oligonucleotide clusters (e.g., Figures $\mathbf{3}$ and 4). All approaches showed that members of the Chloroflexi were ubiquitous across all sites. The relative contribution of Chloroflexus versus Roseiflexus-like organisms varied across different sites, and all sites contained novel organisms from undescribed lineages within the Chloroflexi (discussed in greater detail below). Other phototrophs detected in these sites included populations of Alpha-proteobacteria (Family

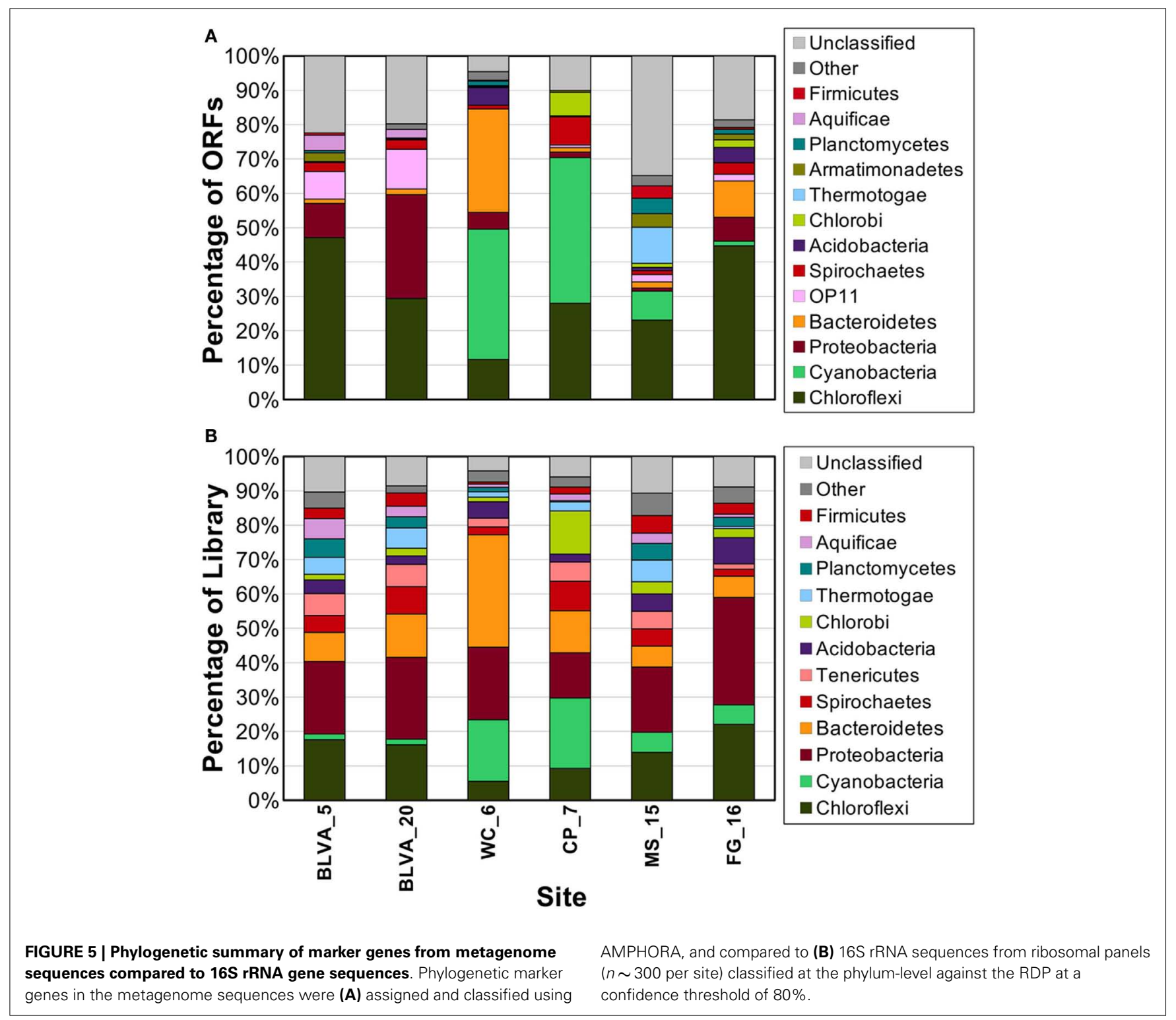


Hyphomicrobiaceae) in FG_16, “Ca. C. thermophilum” (phylum Acidobacteria) (Bryant et al., 2007) in WC_6, and " $\mathrm{Ca}$. T. aerophilum"-like organisms (order Chlorobiales) in MS_15, FG_16 and especially CP_7 (Figure 5B). The MS_15 community contained a Thermotoga-like population as well as several low $\mathrm{G}+\mathrm{C}$ organisms that have not yet been characterized. Although the subsurface mat community from FG_16 contained a novel high $\mathrm{G}+\mathrm{C}$ proteobacterial population not seen in the other sites (Figure 2), these sequences could not be linked unambiguously to the Hyphomicrobiaceae $16 \mathrm{~S}$ rRNA sequences described above, due to inadequate sequence coverage of this population and the lack of a good reference genome that would undoubtedly have assisted in sequence identification.

The distribution of phylogenetically unique Chloroflexi-like $16 \mathrm{~S}$ rRNA gene sequences across sites was compared to the abundance of Chloroflexi marker genes in the metagenome assemblies identified using AMPHORA (Figure 6). The majority of Chloroflexi-like 16S rRNA sequences were most similar to either Chloroflexus or Roseiflexus spp; however, many sequences fell outside of the family Chloroflexaceae and grouped with other members of the Chloroflexi that are not known to exhibit phototrophy (Figure 6). Additionally, Roseiflexus-like populations from MS_15, CP_7, and FG_16 and Chloroflexus-like populations

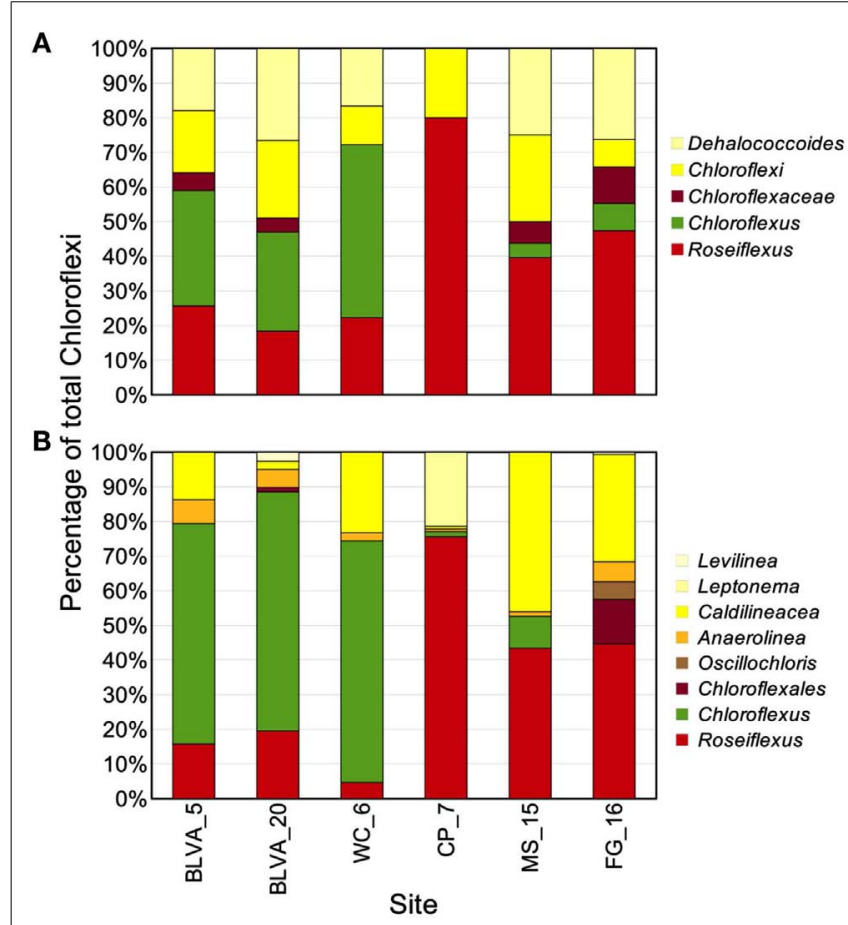

FIGURE 6 | Comparison of Chloroflexi phylogenetic marker genes from metagenomes and Chloroflexi 16S rRNA clones. Phylogenetic marker genes within the metagenome sequences assigned to the phylum Chloroflexi using AMPHORA (A) compared to the identity (confidence threshold of $80 \%$ ) of Chloroflexi-like $16 \mathrm{~S}$ rRNA genes (B) observed in the ribosomal clone library ( $n \sim 300$ per site). Taxonomic groups of Chloroflexi: red $=$ Roseiflexus spp., green $=$ Chloroflexus spp., brown shades $=$ other taxa within the order Chloroflexales, and yellow shades =other taxa within phylum Chloroflexi. from BLVA and WC_6 each formed monophyletic groups that excluded sequences from all other springs (Figure A7 in Appendix). Other spring-specific clades were observed for sequences from FG_16 within the class Anaerolineae, a group of Chloroflexi that was very recently shown to contain phototrophic members (Klatt et al., 2011). The presence of these 16S rRNA gene sequences, combined with observed Chloroflexi-like photosynthesis genes associated with these populations, suggests that these undescribed Chloroflexi may also contribute to phototrophy in these mat communities.

\section{FUNCTIONAL ANALYSIS OF PREDOMINANT SEQUENCE ASSEMBLIES Carbon fixation}

The gene content of major scaffold clusters provides a basis for inferring the possible metabolic functions of dominant populations present in these communities (Table 3). For example, genes encoding key enzymes involved in the 3-hydroxypropionate (3-HP) pathway of inorganic carbon fixation were present in the metagenomes from all six sites, and were associated with the predominant Chloroflexus and Roseiflexus-like populations present in these habitats. Genes coding for subunits of ribulose 1,5-bisphosphate carboxylase-oxygenase (RuBisCO), a key enzyme in the reductive pentose phosphate pathway (i.e., Calvin-Benson-Bassham cycle) were observed only in cyanobacterial (WC_6 and CP_7) or proteobacterial sequences (alphaproteobacteria and Thermochromatium spp. in FG_16 and BLVA_20, respectively). No $\mathrm{CO}_{2}$ fixation genes were associated with the sequences derived from the " $\mathrm{Ca}$. T. aerophilum"-like populations from CP_7, despite the fact that other cultivated members of this phylum are capable of fixing $\mathrm{CO}_{2}$ via the reductive tricarboxylic acid (rTCA) cycle. The average coverage of " $\mathrm{Ca}$. T. aerophilum"-assemblies $(\sim 3 \times)$ may not be sufficient to conclude that these Chlorobi definitively lack the capacity to fix inorganic carbon, however, metatranscriptomic studies with much deeper coverage also failed to identify key genes (i.e., ATP-citrate lyase) of the rTCA cycle in these populations at Mushroom Spring (Liu et al., 2012). This organism is a member of a novel, family level lineage of the Chlorobi, which are predicted to be aerobic photoheterotrophs that cannot oxidize sulfur compounds, cannot fix $\mathrm{N}_{2}$, and do not fix $\mathrm{CO}_{2}$ autotrophically (Liu et al., 2012).

\section{Chlorophototrophy}

Genes involved in (bacterio)chlorophyll biosynthesis and the production of photosynthetic reaction centers (here termed chlorophototrophy genes) were present in scaffold clusters corresponding to Roseiflexus, Chloroflexus, Thermochromatium, and Synechococcus spp., as well as the "Ca. T. aerophilum"-like population in CP_7, and other Cyanobacteria, especially in WC_6 (Table 3). Consequently, the dominant phototrophs within each community exhibit genomic capability for chlorophototrophic metabolism. Examination of shorter $(<10 \mathrm{kbp})$ scaffolds revealed additional genes involved in chlorophototrophy, and these were assigned to specific chlorophototrophic organisms such as " $\mathrm{Ca}$. Chloracidobacterium spp." present in WC_6, and uncultivated proteobacteria in the FG_16 subsurface mat community (Table 3). The high $\mathrm{G}+\mathrm{C} \%$ proteobacterial sequences from FG_16 averaged $74 \%$ identity (AA) to Rhodopseudomonas palustris and other 
Table 3 | Phylogenetic distribution of autotrophic, phototrophic, and sulfur cycling genes in metagenomes.

\begin{tabular}{|c|c|c|c|c|c|c|}
\hline Phylogenetic Group & $\begin{array}{l}\text { BLVA Green } \\
\text { (BVLA_5) }\end{array}$ & $\begin{array}{l}\text { BLVA Purple } \\
\text { (BVLA_20) }\end{array}$ & $\begin{array}{l}\text { White Creek } \\
\text { (WC_6) }\end{array}$ & $\begin{array}{l}\text { Chocolate Pots } \\
\text { (CP_7) }\end{array}$ & $\begin{array}{l}\text { Mushroom } \\
\text { Spring (MS_15) }\end{array}$ & $\begin{array}{l}\text { Fairy Geyser } \\
\text { (FG_16) }\end{array}$ \\
\hline \multicolumn{7}{|c|}{ CARBON FIXATION PATHWAYS } \\
\hline Chloroflexus spp. & 1.00 & 1.00 & 0.80 & & & \\
\hline Other Chloroflexi & & & & 0.20 & & 0.50 \\
\hline Cyanobacteria & & & 0.20 & 0.60 & & \\
\hline Alpha-proteobacteria & & & & & & 0.67 \\
\hline \multicolumn{7}{|c|}{ (BACTERIO)CHLOROPHYLL BIOSYNTHESIS } \\
\hline Roseiflexus spp. & 0.76 & 0.57 & 0.14 & 0.86 & 0.57 & 0.76 \\
\hline Chloroflexus spp. & 1.00 & 0.90 & 0.76 & & 0.19 & 0.05 \\
\hline Other Chloroflexi & & & 0.14 & 0.14 & 0.14 & 0.43 \\
\hline Alpha-proteobacteria & & & & & & 0.25 \\
\hline \multicolumn{7}{|c|}{ PHOTOSYSTEM REACTION CENTERS } \\
\hline Roseiflexus spp. & 0.50 & 0.25 & & 0.50 & & 0.50 \\
\hline Chloroflexus spp. & 0.40 & 0.40 & 0.20 & & & \\
\hline Cyanobacteria & & & 0.33 & 0.97 & 0.52 & 1.00 \\
\hline \multicolumn{7}{|l|}{ SULFUR CYCLING } \\
\hline Thermochromatium spp. & & 0.80 & & & & \\
\hline
\end{tabular}

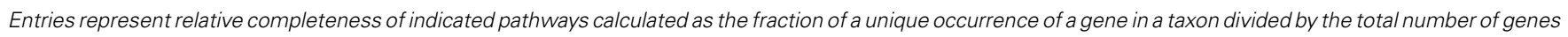

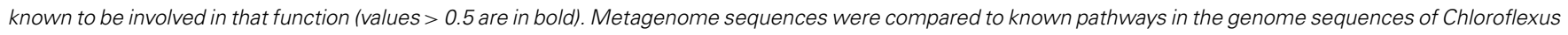

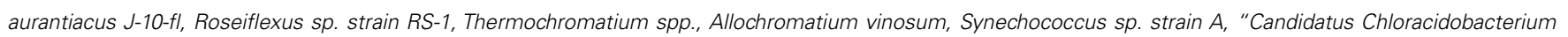
thermophilum," Chloroherpeton thalassium, and the alpha-proteobacterium, Rhodopseudomonas palustris TIE-1.

alpha-proteobacterial genomes, and are likely contributed from the Hyphomicrobiaceae population in FG_16. Genes from Chloroflexi coding for chlorophototrophic functions, but too divergent to originate from either Chloroflexus or Roseiflexus spp. (i.e., only $\sim 70 \%$ AA ID), were present in all non-sulfidic sites, especially in FG_16 (Table 3). The Chloroflexi-like chlorophototrophy genes from FG_16 are phylogenetically distinct ( $<70 \%$ AA ID) from previously described metagenome sequences and all related sequences residing in public databases, indicating that novel uncultured phototrophic members of the Chloroflexi inhabit the mats at Fairy Geyser. Three deduced protein sequences from the subsurface layer in Mushroom Spring (MS_15) were highly similar (96-100\% AA ID) to translated sequences of novel chlorophototrophy genes observed in recent "meta-omic" studies of the top-layers of this same mat type (Klatt et al., 2011; Liu et al., 2011); these observations linked these genes to a group within the Chloroflexi not previously known to contain chlorophototrophic organisms.

\section{Iron oxidation}

One goal of this study was to investigate the role of anoxygenic photosynthesis in sulfidic communities from Bath Lake Vista Annex and in iron mats at Chocolate Pots. Previous studies near the source of Chocolate Pots (and near CP_7) have shown that the oxidation of aqueous $\mathrm{Fe}$ (II) is abiotic, but mediated by the production of oxygen by cyanobacteria (Pierson et al., 1999; Trouwborst et al.,
2007). However, voltammetric microelectrode studies revealed that $\mathrm{Fe}$ (II) persists in deeper layers of the mat, providing a potential niche for anoxygenic phototrophs that can use Fe(II) as an electron donor for photosynthesis (photoferrotrophy) (Trouwborst et al., 2007). Query genes for both sulfur and Fe(II) oxidation (Croal et al., 2007; Jiao and Newman, 2007; Frigaard and Dahl, 2009; Grimm et al., 2011; Bryant et al., 2012) were used to search for evidence of sulfide or Fe(II) oxidation in the community from CP_7. No genes with significant similarity to the photosynthetic iron oxidation (pio) operon of the purple non-sulfur Rhodopseudomonas palustris TIE-1 (Jiao and Newman, 2007) or the fox operon of the purple non-sulfur Rhodobacter ferrooxidans SW2 (Croal et al., 2007) were observed in CP_7, or any site described in this study with the exception of one sequence in FG_16, a site that contains below detectable levels of iron (Table 1). This result concurs with the low numbers of alpha-proteobacterial sequences in CP_7 (Table 3), and the lack of Fe(II) oxidation when similar mats were illuminated with near-infrared radiation to excite bacteriochlorophylls (Trouwborst et al., 2007). To date, no thermophilic representatives of purple and green photoferrotrophs have been discovered.

\section{Sulfur oxidation}

Genes known to encode proteins involved in sulfur oxidation $(d s r$ complex) in some anoxygenic phototrophs (e.g., gammaproteobacterium Allochromatium vinosum, Dahl et al., 
2005; Frigaard and Dahl, 2009; Gregersen et al., 2011) were identified in the Thermochromatium-like population from BLVA_20, and this is consistent with the high concentrations of DS $(>100 \mu \mathrm{M})$ measured in situ. However, the dominant Chloroflexus-like populations observed in both BLVA samples do not contain $d s r$ or sox genes known to be involved in the oxidation of reduced-sulfur compounds. This is consistent with the absence of these same genes in reference Chloroflexus and Roseiflexus spp. genomes (van der Meer et al., 2010; Tang et al., 2011). However, the Chloroflexus assemblies from BLVA_20 and Roseiflexus assemblies of CP_7 (as well as FAP reference genomes) contain sqr genes, which encode sulfide-quinone oxidoreductases and have been suggested to play a role in the oxidation of sulfide to elemental sulfur in multiple bacterial phyla (Griesbeck et al., 2002; Chan et al., 2009; Marcia et al., 2009). Consequently, it is possible that proteins encoded by $s q r$ genes may enable FAPs to obtain electrons from reduced-sulfur compounds (Frigaard and Dahl, 2009; Gregersen et al., 2011; Bryant et al., 2012). In the current study, the presence of similar Chloroflexus as well as similar Roseiflexus populations across both sulfidic and non-sulfidic sites argues that utilization of sulfide as an electron source is not an obligate physiological trait across these genera.

\section{Anaerobic metabolism}

Sequence clusters corresponding to undescribed organisms from the Bacteroidetes show no evidence of chlorophototrophy, but rather contain genes suggestive of anaerobic metabolism(s). Protein-coding genes involved in the oxidation and/or fermentation of organic acids were noted in several sites. For example, acyl-CoA synthetases and lactate dehydrogenases were found in unidentified clusters from BLVA $(\mathrm{G}+\mathrm{C}=64 \%)$ and $\mathrm{CP}_{-} 7$ $(\mathrm{G}+\mathrm{C}=31 \%)$ and a mixed cluster containing sequences from BLVA and CP $(G+C=36 \%)$. Subunits of a pyruvate ferredoxin: oxidoreductase (PFOR) were found in both unidentified BLVA clusters. Although important in every mat type, insufficient coverage of the less-dominant anaerobic populations present in chlorophototrophic mats precludes a thorough analysis of their metabolic potential.

\section{COMPARATIVE ANALYSIS OF PROTEIN FAMILIES}

A complete functional analysis was performed (using multivariate statistical analysis) by assigning TIGRFAM protein families to predicted proteins within all metagenome assemblies. Differences in gene contents among the six chlorophototrophic mats should be indicative of changes in community structure and the corresponding functional attributes of dominant community members. PCA was used to examine the relative differences among sites based on all TIGRFAM categories (Figure 7). Factor 1 (PC1, accounting for $\sim 41 \%$ of the relative functional variation across sites) separates subsurface from surface mat communities, while PC2 ( $\sim 27 \%$ of variation) separates the sites according to different levels of oxygen (or sulfide) and the presence of oxygenic phototrophs. Factor 3 (PC3, 17\% of variation) emphasizes functional similarities between MS_15 and WC_6 that are difficult to separate based only an examination of the abundance of different phylotypes across these sites (e.g., Figure 2). For example, although both sites contained cyanobacteria (e.g., low sulfide),
MS_15 contained more sequences related to Roseiflexus spp., while WC_6 contained numerous Chloroflexus-like sequences. These populations may be organotrophic in this environment and not dependent on sulfide or elemental sulfur (Table 1; Figure 6).

Specific TIGRFAM categories responsible for differences across sites were also evaluated using hierarchical cluster analysis. Two approaches were evaluated using either a smaller set of TIGRFAM categories related to "energy metabolism" (Figure 8) or all TIGRFAM families (Figure A8 in Appendix). In each case, communities (sites) clustered as expected based on replication of specific variables such as sulfide/oxygen, temperature, and mat sample depth (Inskeep et al., 2013). The relative abundance of TIGRFAMs associated with "energy metabolism" was evaluated and included genes related to sugar degradation, glycolysis/gluconeogenesis, pentose phosphate pathway, fermentative processes, electron transport, and chemolithoautotrophy (Figure 8). Site clustering using these TIGRFAMs confirmed greater metabolic potential for processes such as aerobic metabolism and oxygenic photosynthesis in CP_7 and WC_6, samples that contained the most cyanobacteria (e.g., Synechococcus, Fischerella). Conversely, the subsurface mat communities (FG_16 and MS_15) exhibited a greater abundance of genes related to the Entner-Doudoroff pathway and fermentative processes, which are expected to be more important in subsurface environments occurring just below the predominant cyanobacterial populations (See Materials and Methods). Relative abundance within the TIGRFAM category "aerobic metabolism" revealed greater numbers of these genes in sites that contained significant levels of dissolved oxygen (i.e., no DS) compared to sulfidic sites (BLVA_5, 20). Moreover, TIGRFAMs associated with "anaerobic metabolism" as well as "chemoautotrophy" were higher in the sulfidic sites (BLVA sites 5 and 20) (Figure 8), although some of these TIGRFAMs are also present in subsurface mat communities. As should be clear, specific inferences on the basis of a TIGRFAM assignment must be followed with further analysis of the specific gene or set of genes responsible for the abundance estimates within a category.

Hierarchical cluster analysis across all TIGRFAMs grouped into 52 functional categories showed generally similar results regarding site clustering, but the number of TIGRFAM categories used in the analysis precludes a full description of all protein families (Figure A8 in Appendix). Based on clear differences in the phylotypes observed in sulfidic (hypoxic) vs. oxic samples, the TIGRFAM abundance profiles from BLVA (sites 5 and 20), and those from CP_7 and WC_6 formed separate clusters as expected. However, relative TIGRFAM abundance profiles of the subsurface mat communities (FG_16 and MS_15) did not form a separate cluster, as these sites simply do not exhibit greater similarity to one another compared to similarity among all sites (e.g., organisms similar to Roseiflexus spp. are present in all sites). Despite similarities in physical context, the two subsurface communities (MS_15, FG_16) revealed different functional signatures consistent with substantial differences in community composition described above (Figure 2), and that are likely due to differences in geochemistry and temperature between the two samples (FG_16 is $\sim 15^{\circ} \mathrm{C}$ cooler than MS_15 and exhibits higher $\mathrm{pH}$ values, above $\mathrm{pH} 9$ ). Consequently, the functional profiles across all TIGRFAM groupings are consistent with, and provide further support for, the 


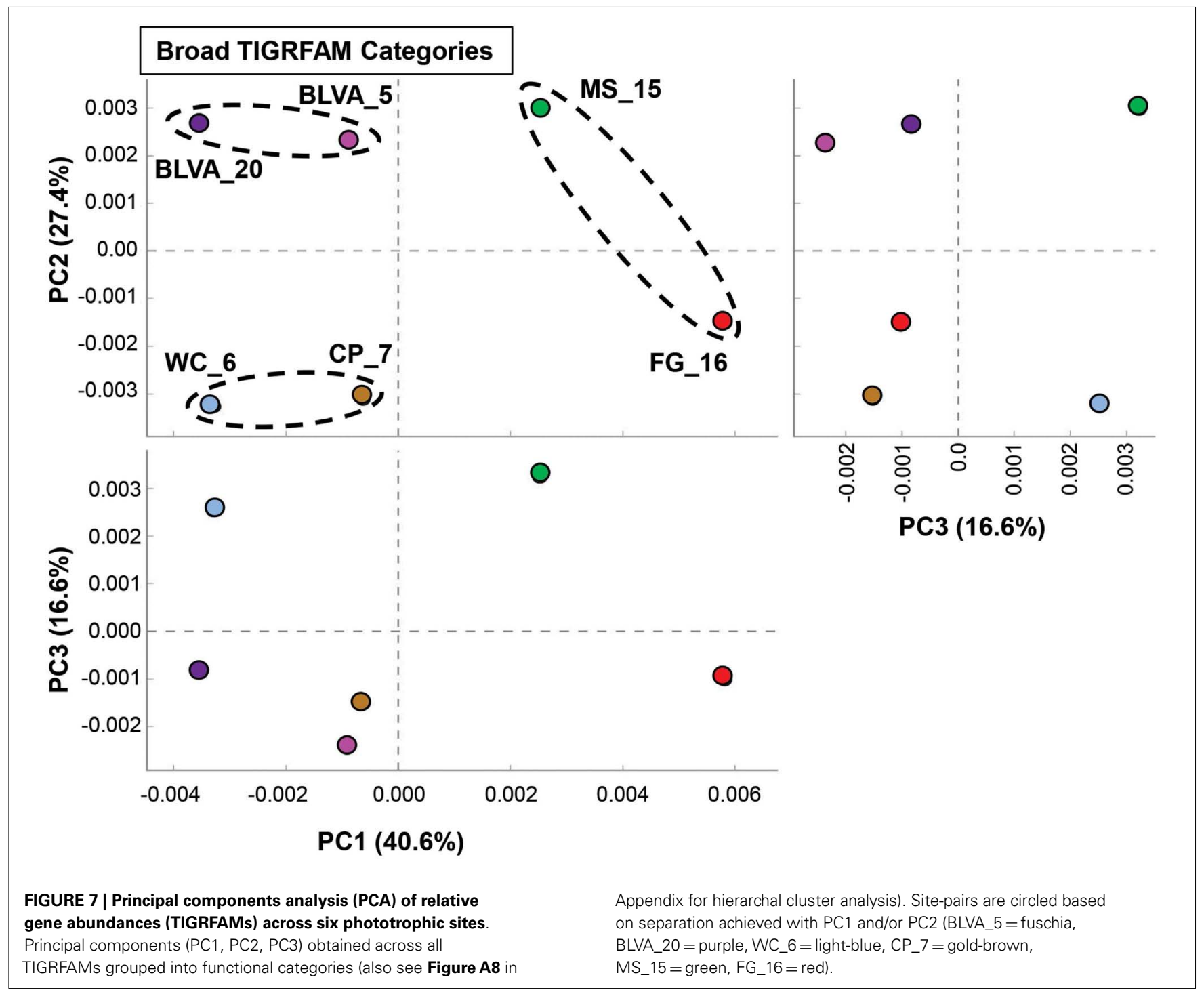

differences in community structure between MS_15 and FG_16 (Figure A8 in Appendix).

\section{DISCUSSION}

The six sites investigated in this study are representative of three general types of geothermal springs in Yellowstone National Park that support bacterial chlorophototrophic communities and include (i) alkaline-siliceous chloride springs ( $\mathrm{pH}$ 7.5-9; e.g., WC_6, MS_15, and FG_16), (ii) sulfidic-carbonate springs ( $\mathrm{pH}$ 6-7; e.g., BLVA_5 and BLVA_20), and (iii) mildly acidic ( $\mathrm{pH} 6$ ) non-sulfidic springs containing high aqueous $\mathrm{Fe}(\mathrm{II})$ (e.g., CP_7) (Rowe et al., 1973; McClesky et al., 2005). The major physical and geochemical constraints that have been postulated to control the distribution of phototrophs (and photosynthesis) in these thermal springs are $\mathrm{pH}$, temperature, sulfide concentration, and gradients in light and/or other chemicals existing as a function of mat depth (Brock, 1967, 1978; Cox et al., 2011; Boyd et al., 2012). The upper temperature limit of cyanobacterial photosynthesis is known to occur at $\sim 74^{\circ} \mathrm{C}$ (Brock, 1973), and the grazing of these microbial mats by eukaryotic organisms typically only occurs at temperatures below $50^{\circ} \mathrm{C}$. Most springs that support bacterial chlorophototrophic mats occur at $\mathrm{pH}>5$, with rare exceptions such as the acid-tolerant, purple non-sulfur phototrophs related to Rhodopila sp. observed in Nymph Lake (YNP) and in small sulfidic, acidic ( $\mathrm{pH}$ 3.5-4.5) springs near the Gibbon River (Pfennig, 1974; Madigan et al., 2005). The bulk aqueous pH at CP_7 is near the lower limit observed for thermophilic cyanobacteria (Brock, 1973), and microelectrode measurements of the CP_7 mat revealed that it was constantly flushed by vent water with a $\mathrm{pH} \sim 6$ (Trouwborst et al., 2007). Even at pH 6, CP_7 supports an active community of cyanobacteria that are similar to Synechococcus sp. $\mathrm{B}^{\prime}$-like populations observed in Mushroom and Octopus Spring $(\mathrm{pH}>8)$ phototrophic mats (Figure A1 in Appendix).

\section{DISTRIBUTION OF ANOXYGENIC PHOTOTROPHS}

Anoxygenic chlorophototrophs are known to colonize sulfidic springs of YNP (van Niel and Thayer, 1930; Castenholz, 1969, 1977; Madigan, 1984; Giovannoni et al., 1987), and this was 


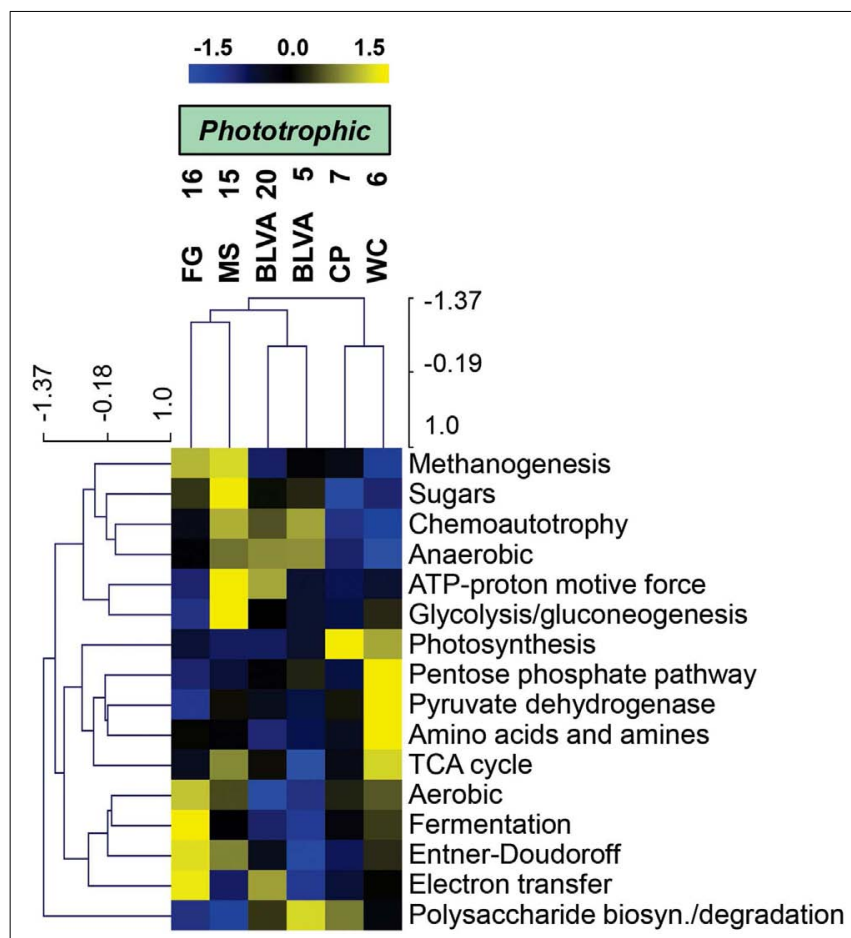

FIGURE 8 | Hierarchical cluster analysis of relative abundances of genes in TIGRFAMs associated with "Energy Metabolism" classified by functional category. Data was standardized by functional category before clustering to avoid biasing analysis by a few categories with high gene abundance. Pearson correlation was used as the distance measure for average linkage agglomerative clustering.

confirmed in samples from BLVA in which concentrations of DS exceeded $100 \mu \mathrm{M}$. However, the only population with genes supporting a complete, well-studied sulfide-oxidization pathway (Dahl et al., 2005) was the Thermochromatium-like organisms present in BLVA_20. The other prominent anoxygenic chlorophototrophs included populations of Chloroflexus and Roseiflexus-like spp. (identified across all sites). The abundance of chlorophototrophic Chloroflexi across sites is reflective of their previously established physiological diversity, including photoheterotrophy with organic acids such as acetate and propionate, photoautotrophy, photomixotrophy, and oxic and anoxic chemoorganotrophy (Madigan et al., 1974; Pierson and Castenholz, 1974; Giovannoni et al., 1987; Hanada et al., 2002; van der Meer et al., 2003, 2010; Zarzycki and Fuchs, 2011). While these organisms are generally photoheterotrophic, their metabolic flexibility contributes in part to their ability to colonize a broad spectrum of slightly acidic to neutral $\mathrm{pH}$ environments at $50-70^{\circ} \mathrm{C}$ (Castenholz and Pierson, 1995). Highly similar (>98\% average NT ID) Roseiflexus-like organisms were abundant in all sites, independent of bulk sulfide concentration. Moreover, Chloroflexus-like populations were found in both sulfidic (BLVA) and oxic systems (WC_6). The presence of Roseiflexus spp. sequences in BLVA_5 and_20 and the larger proportion of Chloroflexus spp. in WC_6 compared to Roseiflexus spp. was unexpected, as it has been shown that Chloroflexus spp. tolerate higher levels of sulfide in culture (Madigan et al., 1974; Giovannoni et al., 1987; van der Meer et al., 2010). These results suggest that sulfide concentration is not a deterministic variable explaining niche partitioning between Chloroflexus spp. and Roseiflexus spp. This inconsistency with expected distribution patterns implies that factors other than sulfide and/or oxygen are important in controlling the relative abundance of Chloroflexus and Roseiflexus spp. in YNP phototrophic mat environments. Finally, sequences assigned to "Ca. C. thermophilum" (phylum Acidobacteria) (Bryant et al., 2007) were most abundant in the oxic communities of WC_6 and MS_15 ( 8 and 3\% of sequences, respectively). Although small numbers of sequences $(<1 \%)$ assigned to this organism (BLASTN, $>50 \%$ NT ID) were observed in other sites, genes encoding enzymes of (B)Chl biosynthesis and belonging to "Ca. C. thermophilum" were only found in WC_6 and MS_15 (Table 3).

The observed differences in functional gene content between the two subsurface mat communities (MS_15 and FG_16) were of further interest, in part due to the presence of different poorly understood organisms in both sites. "Red-layer" communities (FG_16) have been shown to contain novel phototrophs (Boomer et al., 2000, 2002), whose pigments exhibit unusual in vivo absorption spectra (Boomer et al., 2000). Indeed, the FG_16 sample contained a high G $+\mathrm{C}(\sim 68-70 \%)$ alpha-proteobacterial population not observed in any other site (Figure 2). The 16S rRNA sequences from FG_16 indicated the presence of an alphaproteobacterium (family Hyphomicrobiaceae), some members of which are known to produce BChl $b$ (Hiraishi, 1997). BChl $b$ pigments were detected in solvent-based extractions from Fairy Geyser mat samples (M. Pagel and D. A. Bryant, unpublished data) and suggest that the phototrophs producing these pigments may exhibit light-harvesting properties that differ from those of other chlorophototroph populations in the mats.

Differences in community composition between the two subsurface mat communities may be driven by differences in temperature ( 60 vs. $36-40^{\circ} \mathrm{C}$ in MS_15 and FG_16, respectively). However, the MS_15 subsurface community was also distinct from surface (top 1-2 $\mathrm{mm}$ ) communities sampled from the same mats at the same temperature (Klatt et al., 2011). For example, the abundance of Thermotoga spp. in the subsurface communities may be driven primarily by lower oxygen levels shown to exist $2 \mathrm{~mm}$ below the mat surface (Jensen et al., 2011) and is consistent with their physiology as microaerophilic heterotrophs (van Ooteghem et al., 2004). Anaerobic fermentation by Thermotoga spp. could constitute a major source of $\mathrm{H}_{2}$ that could enable photomixotrophic metabolism by Chloroflexus and Roseiflexus spp. (Klatt et al., 2013). Moreover, compared to the phototrophic surface layers of these mats, MS_15 subsurface communities contained fewer Synechococcus spp., greater Roseiflexus spp., and greater numbers of likely anaerobic or fermentative organisms within the Bacteroidetes and Thermodesulfobacteria.

\section{TROPHIC INTERACTIONS}

Trophic interactions between FAPs and cyanobacteria have been studied in phototrophic geothermal mats, and it has been shown that photoheterotrophs (FAPs) utilize organic acids produced by autotrophic cyanobacteria (Anderson et al., 1987; Nold and 
Ward, 1996; van der Meer et al., 2005). Moreover, it has been proposed that Thermochromatium spp. (purple-sulfur bacteria) are primary producers in sulfidic springs and cross-feed lowmolecular weight organic acids to FAPs (Madigan et al., 1989, 2005). This is analogous to the cyanobacterial primary production and trophic interactions documented to occur in Octopus Spring and Mushroom Spring (van der Meer et al., 2005). However, this hypothesis is not supported by the relatively heavy carbon isotope composition of Chloroflexaceae-specific lipid biomarkers in sulfidic springs $\left(\delta^{13} \mathrm{C}=-8.9\right.$ to $-18.5 \%$, van der Meer et al., 2003). These isotopic compositions have been interpreted to be too heavy to originate from compounds cross-fed from Thermochromatium spp., which use the Calvin-BensonBassham cycle for carbon dioxide fixation $\left({ }^{13} \mathrm{C}=-20\right.$ to -35 $\%$ ). The lipid signatures are more readily explained by direct carbon dioxide fixation by Chloroflexus and Roseiflexus spp. via the 3-HP pathway (Holo and Sirevåg, 1986; Strauss and Fuchs, 1993; van der Meer et al., 2000, 2010). Metagenome sequence assemblies obtained in the current study showed that these uncultivated Chloroflexus and Roseiflexus spp. contained all genes necessary for $\mathrm{CO}_{2}$ fixation via the 3-HP pathway (Table 3), and is consistent with earlier evidence at BLVA of short-term, sulfidestimulated ${ }^{14} \mathrm{CO}_{2}$ incorporation by FAPs (Giovannoni et al., 1987). Collectively, these observations support the hypothesis that all major chlorophototrophs contribute to primary productivity in sulfidic-carbonate springs (Table 3). It remains to be determined whether FAPs are more important contributors to primary productivity in these systems when purple-sulfur bacteria (i.e., Thermochromatium) and cyanobacteria are both absent (such as observed in BLVA_5).

This study highlights several of the major differences in community composition and structure, and potential function of chlorophototrophic microbial mats sampled from hightemperature systems $\left(40-60^{\circ} \mathrm{C}\right)$ containing high sulfide, high $\mathrm{Fe}(\mathrm{II})$, or high dissolved oxygen. The distribution of chlorophototrophic organisms, as would be expected, is dependent on the presence or absence of high sulfide (cyanobacteria, purple-sulfur bacteria), and position within laminated mats (e.g., FAPs, Bacteroidetes, and Firmicutes). Temperature was not particularly well constrained as a consistent parameter for comparisons across the sites included in this study. However, the ubiquity of Chloroflexus and Roseiflexus spp. across all sites emphasizes their ability to tolerate large differences in not only temperature, but extremes between high and low levels of DS and/or oxygen. Assemblies of a novel Chlorobi population ("Ca. T. aerophilum") from the high iron site at Chocolate Pots (CP_7) were similar to those obtained from Mushroom Spring and Octopus Spring (Liu et al., 2012). These populations deserve further study, especially considering their phylogenetic distance and different functional attributes compared to other currently described members of the Chlorobi. The dominant cyanobacteria observed across these sites (found exclusively in non-sulfidic systems) included Synechococcus spp. (CP_7, MS_15) and Fischerella (Mastigocladus) spp. (WC_6). Consequently, sulfide is a critical geochemical variable that selects against the presence of cyanobacteria and provides niche opportunities for other chlorophotoautotrophs. Other poorly represented organisms in the current study include bacteria from the phyla Firmicutes and
Bacteroidetes, and although the assemblies for organisms within these phyla were not particularly large, a sufficient number of genes were found to infer that their role in these communities may involve fermentation and the degradation of complex carbon compounds. Additional sequence assembly and/or isolation of these populations, coupled with site-specific studies, are necessary to clarify the important carbon cycling functions that these populations conduct and the processes that drive interactions among primary producers and secondary consumers in chlorophototrophic mats.

\section{MATERIALS AND METHODS SAMPLE COLLECTION AND GEOCHEMICAL ANALYSES}

Six different samples were obtained from five hot springs between August 2007 and May 2008 (Table 1; Table S2 in Inskeep et al., 2013) and immediately frozen in liquid $\mathrm{N}_{2}$. Phototrophic mats were sampled at different locations relative to the source of each respective spring, and two samples were obtained from subsurface mat layers [Mushroom Spring (MS_15) and Fairy_Geyser (FG_16)]. The subsurface layers were obtained by careful removal of the top $2 \mathrm{~mm}$ green layer with a sterile scalpel and separation of a definitive under-layer in each mat type (e.g., Boomer et al., 2000, 2002; Nübel et al., 2002). Geochemical characterization was performed on bulk spring water at each sampling location after filtration $(0.2 \mu \mathrm{m})$. Total dissolved ions were determined using inductively coupled plasma spectrometry and major anions determined using ion chromatography as described previously (Macur et al., 2004; Inskeep et al., 2005). Temperature, $\mathrm{pH}$, total DS, total soluble Fe, and dissolved oxygen were determined immediately in the field. Dissolved gases $\left(\mathrm{CO}_{2}, \mathrm{CH}_{4}\right.$, and $\left.\mathrm{H}_{2}\right)$ were determined using headspace gas chromatography of filtered field samples (Inskeep et al., 2005).

\section{DNA EXTRACTION AND PREPARATION}

Environmental DNA was extracted as described in Inskeep et al. (2013). Briefly, 0.5-1 g of frozen mat samples were processed using separate parallel DNA extractions with an enzymatic method (Proteinase $\mathrm{K}(1 \mathrm{mg} / \mathrm{ml})$ with $\mathrm{Na}$-dodecyl sulfate (SDS) $(0.3 \%$ $\mathrm{w} / \mathrm{v}$ ) for $0.5 \mathrm{~h}$ at $37^{\circ} \mathrm{C}$ ) and a mechanical method (bead-beating with $2 \% \mathrm{w} / \mathrm{v}$ SDS and $15 \% \mathrm{v} / \mathrm{v}$ Tris-HCl-equilibrated phenol, shaken at $5.5 \mathrm{~m} / \mathrm{s}$ for $30 \mathrm{~s}$ ) for cell lysis. The resulting cell lystates were pooled and subsequent DNA extractions were performed with phenol:chloroform:isoamyl alcohol (25:24:1), and chloroform:isoamyl alcohol (24:1). This procedure removed DNA extraction bias that has been shown to occur when only mechanical or enzymatic protocols are used for cell lysis (Klatt et al., 2007, 2011). All samples were treated with RNAse I (Promega, Madison, WI, USA), and DNA was precipitated with ethanol and Na-acetate. Small-insert $(3 \mathrm{~kb})$ metagenome libraries were constructed as described in Inskeep et al. (2013). About 820 bp was sequenced at each end of the inserts in the library clones, which produced pairs of linked sequences (424,982 sequences) that represented a total dataset of $\sim 320.6 \mathrm{Mbp}$. Ribosomal (16S rRNA) gene sequence libraries were constructed by PCR amplification using universal primers targeting domains Archaea (4aF, TCCGGTTGATCCTGCCRG; 1391R, GACGGGCRGTGWGTRCA) and Bacteria (27F, AGAGTTTGATCCTGGCTCAG and 1391R). Amplicons 
were cloned using the TOPO TA Cloning Kit (Invitrogen, Carlsbad CA USA) and sequenced using Big Dye v3.1 chemistry (Applied Biosystems, Foster City, CA, USA).

\section{PRE-ASSEMBLY METAGENOME SEOUENCE ANALYSES}

All metagenome sequences were used as queries in a "blastx" (Camacho et al., 2009) search against the NCBI nr database (accessed 22 March 2011) with default parameters. The results were parsed and visualized with the MEGAN software version 2.3.2 (Huson et al., 2007) with the default parameters (MinScore $=35.0$, TopPercent $=10.0$, MinSupport $=5$ ) and taxonomic assignments of the top "blastx" matches were extracted. Comparative analysis was also completed using several relevant reference genomes available after this date (e.g., Fischerella sp. and "Ca. T. aerophilum"; Liu et al., 2012).

\section{SEQUENCE ASSEMBLY AND ANNOTATION}

Metagenomic scaffolds of overlapping end sequences were constructed separately for each of the six samples using the Celera assembler (Miller et al., 2008; Inskeep et al., 2013). This resulted in 206,469 scaffolds containing 183.2 Mbp (27-33 Mbp per site) of assembled sequence, or a $57 \%$ compression of the raw sequence data. The DOE-JGI annotation pipeline was used as an initial step for inferring functions for predicted ORFs on metagenome scaffolds, and included open reading frame (ORF) prediction, BLAST alignments, and hidden Markov model analysis (Mavromatis et al., 2009). Translated peptide sequences from predicted ORFs were analyzed with the AMPHORA package (Wu and Eisen, 2008), which identified homologs of 31 different genes (mostly predicted to encode ribosomal proteins or enzymes with housekeeping functions) that could be used as phylogenetic markers. Genes encoding particular functions were identified by BLASTP using reference sequences as queries, with the additional requirement that candidate sequences had a top BLASTP match to a sequence with the same annotated function in the NCBI $\mathrm{nr}$ database. All annotated metagenome sequence assemblies (Celera/PGA) discussed in the current manuscript are available through the DOE-JGI IMG/M (Markowitz et al., 2012) website (http://img.jgi.doe.gov/m) under IMG taxon OID numbers as follows: YNPSite06 (2022920004/2013515000), Site07 (2022920013/2014031006), Site15 (2022920016/2015219002), Site16 (2022920018/2016842003), Site05 (2022920003/201395 4000), Site20 (2022920020/2016842008), and Site17 (2022920021/ 2016842005).

\section{RIBOSOMAL RNA SEQUENCE ANALYSES}

All bacterial 16S rRNA sequences from the 16S rRNA-specific PCR clone libraries were aligned and screened for chimeras with Bellerophon (Huber et al., 2004) with subsequent manual curation. OTUs were determined using the CAP3 assembler (Huang and Madan, 1999) at the 99\% demarcation level. Rarefaction curves were determined, and the Chaol and ACE richness indexes and the Fisher's alpha, Shannon-Weaver, and Simpson's diversity indexes were calculated for each library (EcoSim version 7.0, Gotelli and Entsminger, 2001; EstimateS v. 8.0, Colwell, 2009). The RDP Bayesian Classifier (Wang et al., 2007) was used to assign taxonomy to $16 \mathrm{~S}$ rRNA sequences at the $80 \%$ confidence level (Figures 5B and 6B), and all sequences belonging to the Chloroflexi were aligned with reference sequences corresponding to Escherichia coli positions 29-1349 (1321 positions). Alignments were masked with bacterial complexity filters in ARB (Ludwig et al., 2004). A phylogenetic tree was produced using the BioNJ algorithm (Gascuel, 1997) (Figure 2) and bootstrapped with 1000 replicates. Reference sequences shorter than the initial alignment were subsequently added to the tree using the ARB parsimony tool. Consensus maximum-likelihood trees were produced from 1000 replicate trees using RaxML (Stamatakis, 2006). A maximum-likelihood tree based upon amino acid alignments of PscD sequences was constructed using PhyML (Guindon et al., 2010).

\section{STATISTICAL ANALYSES}

A distance matrix of environmental variables was constructed by calculating Gower coefficients using the $\mathrm{R}$ statistical environment (R Development Core Team, 2012). The Gower coefficient allows for different data types (qualitative presence/absence vs. quantitative numerical) with different dimensional scales to be combined into a general dissimilarity metric (Gower, 1971). Geochemical variables were treated as factors and were correlated to this distance matrix using the envfit function of the vegan package (Oksanen et al., 2012). Metagenomic scaffolds larger than $10 \mathrm{kbp}$ were subjected to analysis using oligonucleotide composition. All possible tri-, tetra-, penta-, and hexanucleotides were counted with custom perl scripts, and normalized to the length of the scaffold. Normalized oligonucleotide composition matrices were subjected to k-means clustering with a range of $k=4-12$ with 100 trials each. Clusters were reported when at least 10 scaffolds grouped together in $90 \%$ or greater Monte-Carlo simulations. The composite summary of these k-means trials was displayed as an interaction network using the program Cytoscape 2.8.1 (Shannon et al., 2003).

\section{BROAD FUNCTIONAL ANALYSIS OF METAGENOME SEQUENCES}

Assembled sequence from each of the phototrophic sites was annotated as described in Inskeep et al. (2010) and predicted proteins from the scaffolds were assigned TIGRFAM protein families (Selengut et al., 2007) using HMMER 3 (Eddy, 2011) with $e$-value cutoff of 1e-6. PCA and statistical analysis of site group differences was performed using the STAMP v2.0 software (Parks and Beiko, 2010). The White's non-parametric T-test and ANOVA tests were used to test for differences between two site groups and multiple site groups respectively. Two-way clustering was performed using row-standardized (across sites) average TIGRFAM category abundance data using the Euclidean distance metric and complete-linkage hierarchical clustering in MeV 4.8 (Saeed et al., 2003) software. Other details regarding TIGRFAM analysis are described in this issue (Inskeep et al., 2013).

\section{ACKNOWLEDGMENTS}

Authors appreciate support from the National Science Foundation Research Coordination Network Program (MCB 0342269), the DOE-Joint Genome Institute Community Sequencing Program (CSP 787081) as well as all individual author institutions and associated research support that together has made this study possible. The work conducted by the U.S. Department of 
Energy Joint Genome Institute is supported by the Office of Science of the U.S. Department of Energy under Contract No. DE-AC02-05CH11231. Authors appreciate research permitting

\section{REFERENCES}

Anderson, K. L., Tayne, T. A., and Ward, D. M. (1987). Formation and fate of fermentation products in hot spring cyanobacterial mats. Appl. Environ. Microbiol. 53, 2343-2352.

Badger, J. H., Hoover, T. R., Brun, Y. V., Weiner, R. M., Laub, M. T., Alexandre, G., et al. (2006). Comparative genomic evidence for a close relationship between the dimorphic prosthecate bacteria Hyphomonas neptunium and Caulobacter crescentus. J. Bacteriol. 188, 6841-6850.

Becraft, E. D., Cohan, F. M., Kuhl, M., Jensen, S. I., and Ward, D. M. (2011). Fine-scale distribution patterns of Synechococcus ecological diversity in microbial mats of Mushroom Spring, Yellowstone National Park. Appl. Environ. Microbiol. 77, 7689-7697.

Bhaya, D., Grossman, A. R., Steunou, A.S., Khuri, N., Cohan, F. M., Hamamura, N., et al. (2007). Population level functional diversity in a microbial community revealed by comparative genomic and metagenomic analyses. ISME J. 1, 703-713.

Boomer, S. M., Lodge, D. P., Dutton, B. E., and Pierson, B. (2002). Molecular characterization of novel red green nonsulfur bacteria from five distinct hot spring communities in Yellowstone National Park. Appl. Environ. Microbiol. 68, 346-355.

Boomer, S. M., Pierson, B. K., Austinhirst, R., and Castenholz, R. W. (2000). Characterization of novel bacteriochlorophyll-a-containing red filaments from alkaline hot springs in Yellowstone National Park. Arch. Microbiol. 174, 152-161.

Boyd, E. S., Fecteau, K. M., and Peters, J. W. (2012). Modeling the habitat range of phototrophs in Yellowstone National Park: toward the development of a comprehensive fitness landscape. Front. Microbiol. 3:221. doi:10.3389/fmicb.2012.00221

Brock, T. D. (1967). Life at high temperatures. Science 158, 1012-1019.

Brock, T. D. (1973). Lower pH limit for the existence of blue-green algae: evolutionary and ecological implications. Science 179, 480-483.

Brock, T. D. (1978). Thermophilic Microorganisms and Life at High Temperatures. New York: Springer Verlag.

Bryant, D. A., Costas, A. M. G., Maresca, J. A., Chew, A. G. M., Klatt, C. G., Bateson, M. M., et al.
(2007). Candidatus Chloracidobacterium thermophilum: an aerobic phototrophic Acidobacterium. Science 317, 523-526.

Bryant, D. A., Klatt, C. G., Frigaard, N.-U., Liu, Z., Li, T., Zhao, F., et al. (2012). "Comparative and functional genomics of anoxygenic green bacteria from the taxa Chlorobi, Chloroflexi, and Acidobacteria," in Functional Genomics and Evolution of Photosynthetic Systems, Vol. 33, Advances in Photosynthesis and Respiration, eds R. L. Burnap and W. Vermaas (Dordrecht: Springer), $47-102$.

Camacho, C., Coulouris, G., Avagyan, V., Ma, N., Papadopoulos, J., Bealer, K., et al. (2009). BLAST+: architecture and applications. BMC Bioinformatics 10:421. doi:10.1186/1471-210510-421

Castenholz, R. W. (1969). Thermophilic blue-green algae and the thermal 476-504.

Castenholz, R. W. (1976). The effect of sulfide on the blue-green algae of hot springs. I. New Zealand and Iceland. J. Phycol. 12, 54-68.

Castenholz, R. W. (1977). The effect of sulfide on the blue-green algae of hot springs II. Yellowstone National Park. Microb. Ecol. 3, 79-105.

Castenholz, R. W., and Pierson, B. K. (1995). "Ecology of thermophilic anoxygenic phototrophs," in Anoxygenic Photosynthetic Bacteria, eds R. E. Blankenship, M. T. Madigan, and C. E. Bauer (Dordrecht: Kluwer Academic Publishers), 87-103.

Chan, L.-K., Morgan-Kiss, R. M., and Hanson, T. E. (2009). Functional analysis of three sulfide:quinone oxiulum tepidum. J. Bacteriol. 191, 1026-1034.

Cohen, Y., and Rosenberg, E. (eds) (1989). Microbial Mats: Physiological Ecology of Benthic Microbial Communities. Washington, DC: American Society for Microbiology.

Colwell, R. K. (2009). EstimateS: Statistical Estimation of Species Richness and Shared Species from Samples. Version 8.0. Available at: http://viceroy.eeb.uconn.edu/ estimates.

Cox, A., Shock, E. L., and Havig, J. R. (2011). The transition to microbial photosynthesis in hot spring ecosystems. Chem. Geol. 280, 344-351. environment. Bacteriol. Rev. 33, doreductase homologs in Chlorobac-

focused on the YNP metagenome project (Permit No, YELL-5568, 2007-2010), and managed by C. Hendrix and S. Guenther (Center for Resources, YNP).

Croal, L. R., Jiao, Y., and Newman, D. K. (2007). The fox operon from Rhodobacter strain SW2 promotes phototrophic $\mathrm{Fe}(\mathrm{II})$ oxidation in Rhodobacter capsulatus SB1003. J. Bacteriol. 189, 1774-1782.

Dahl, C., Engels, S., Pott-Sperling, A. S. Schulte, A., Sander, J., Lübbe, Y., et al. (2005). Novel genes of the $d s r$ gene cluster and evidence for close interaction of Dsr proteins during sulfur oxidation in the phototrophic sulfur bacterium Allochromatium vinosum. J. Bacteriol. 187, 1392-1404.

Eddy, S. R. (2011). Accelerated profile HMM searches. PLoS Comput. Biol. 7:e1002195. doi:10.1371/journal.pcbi.1002195

Frigaard, N., and Dahl, C. (2009). Sulfur metabolism in phototrophic sulfur bacteria. Adv. Microb. Physiol. 54, 103-200.

Garcia Costas, A. M., Liu, Z., Tomsho, L. P., Schuster, S. C., Ward, D. M., and Bryant, D. A. (2012). Complete genome of Candidatus Chloracidobacterium thermophilum, a chlorophyll-based photoheterotroph belonging to the phylum Acidobacteria. Environ. Microbiol. 14, 177-190.

Gascuel, O. (1997). BIONJ: an improved version of the $\mathrm{NJ}$ algorithm based on a simple model of sequence data. Mol. Biol. Evol. 14, 685-695.

Giovannoni, S., Revsbech, N. P., Ward, D. M., and Castenholz, R. W. (1987). Obligately phototrophic Chloroflexus: primary production in anaerobic hot spring microbial mats. Arch. Microbiol. 147, 80-87.

Gotelli, N. J., and Entsminger, G. L. (2001). EcoSim: Null Models Software for Ecology. Version 7.0. Acquired Intelligence Inc. and Kesey-Bear. Available at: http://gary entsminger.com/ecosim/index.htm.

Gower, J. C. (1971). A general coefficient of similarity and some of its properties. Biometrics 27, 857-871.

Gregersen, L. H., Bryant, D. A., and Frigaard, N.-U. (2011). Mechanisms and evolution of oxidative sulfur metabolism in green sulfur bacteria. Front. Microbiol. 2:116. doi:10.3389/fmicb.2011.00116

Griesbeck, C., Schütz, M., Schödl, T., Bathe, S., Nausch, L., Mederer, N., et al. (2002). Mechanism of sulfide-quinone reductase investigated using site-directed mutagenesis and sulfur analysis. Biochemistry 41, 11552-11565.
Grimm, F., Franz, B., and Dahl, C. (2011). Regulation of dissimilatory sulfur oxidation in the purple sulfur bacterium Allochromatium vinosum. Front. Microbiol. 2:51. doi:10.3389/fmicb.2011.00051

Guindon, S., Dufayard, J.-F., Lefort, V., Anisimova, M., Hordijk, W., and Gascuel, O. (2010). New algorithms and methods to estimate maximumlikelihood phylogenies: assessing the performance of PhyML 3.0. Syst. Biol. 59, 307-321.

Hanada, S., Takaichi, S., Matsuura, K., and Nakamura, K. (2002). Roseiflexus castenholzii gen. nov., sp. nov., a thermophilic, filamentous, photosynthetic bacterium that lacks chlorosomes. Int. J. Syst. Evol. Microbiol. 52, 187-193.

Heidelberg, J. F., Nelson, W. C., Schoenfeld, T., and Bhaya, D. (2009). Germ warfare in a microbial mat community: CRISPRs provide insights into the co-evolution of host and viral genomes. PLoS ONE 4:e4169. doi:10.1371/journal.pone.0004169

Henry, E. A., Devereux, R., Maki, J. S., Gilmour, C. C., Woese, C. R., Mandelco, L., et al. (1994). Characterization of a new thermophilic sulfatereducing bacterium Thermodesulfovibrio yellowstonii, gen. nov. and sp. nov.: its phylogenetic relationship to Thermodesulfobacterium commune and their origins deep within the bacterial domain. Arch. Microbiol. 161, 62-69.

Hiraishi, A. (1997). Transfer of the bacteriochlorophyll $b$ containing phototrophic bacteria Rhodopseudomonas viridis and Rhodopseudomonas sulfoviridis to the genus Blastochloris gen. nov. Int. J. Syst. Bacteriol. 47, 217-219.

Holo, H., and Sirevåg, R. (1986). Autotrophic growth and $\mathrm{CO}_{2}$ fixation of Chloroflexus aurantiacus. Arch. Microbiol. 145, 173-180.

Huang, X., and Madan, A. (1999). CAP3: a DNA sequence assembly program. Genome Res. 9, 868-877.

Huber, T., Faulkner, G., and Hugenholtz, P. (2004). Bellerophon: a program to detect chimeric sequences in multiple sequence alignments. Bioinformatics 20, 2317-2319.

Huson, D. H., Auch, A. F., Qi, J., and Schuster, S. C. (2007) MEGAN analysis of metagenomic data. Genome Res. 17, 377-386. 
Inskeep, W. P., Ackerman, G. G., Taylor, W. P., Kozubal, M., Korf, S., and Macur, R. E. (2005). On the energetics of chemolithotrophy in nonequilibrium systems: case studies of geothermal springs in Yellowstone National Park. Geobiology 3, 297-317.

Inskeep, W. P., Jay, Z. J., Tringe, S. G., Herrgard, M. J., Rusch, D. B., et al. (2013). The YNP metagenome project: environmental parameters responsible for microbial distribution in the Yellowstone geothermal ecosystem. Front. Microbiol. 4:67. doi:10.3389/fmicb.2013.00067

Inskeep, W. P., Rusch, D. B., Jay, Z. J., Herrgard, M. J., Kozubal, M. A., Richardson, T. H., et al. (2010). Metagenomes from hightemperature chemotrophic systems reveal geochemical controls on microbial community structure and function. PLOS ONE 5:e9773. doi:10.1371/journal.pone.0009773

Jackson, T. J., Ramaley, R. F., and Meinschein, W. G. (1973). Thermomicrobium, a new genus of extremely thermophilic bacteria. Int. J. Syst. Bacteriol. 23, 28-36.

Jensen, S. I., Steunou, A.-S., Bhaya, D., Kuhl, M., and Grossman, A. R. (2011). In situ dynamics of $\mathrm{O}_{2}, \mathrm{pH}$ and cyanobacterial transcripts associated with CCM, photosynthesis and detoxification of ROS. ISME J. 5, 317-328.

Jiao, Y., and Newman, D. K. (2007). The pio operon is essential for phototrophic $\mathrm{Fe}(\mathrm{II})$ oxidation in Rhodopseudomonas palustris TIE-1. J. Bacteriol. 189, 1765-1773.

Jones, D. T., Taylor, W. R., and Thornton, J. M. (1992). The rapid generation of mutation data matrices from protein sequences. Comput. Appl. Biosci. 8, 275-282.

Klatt, C. G., Bryant, D. A., and Ward, D. M. (2007). Comparative genomics provides evidence for the 3-hydroxypropionate autotrophic pathway in filamentous anoxygenic phototrophic bacteria and in hot spring microbial mats. Environ. Microbiol. 9, 2067-2078.

Klatt, C. G., Liu, Z., Ludwig, M., Kühl, M., Jensen, S. I., Bryant, D. A., et al. (2013). Temporal metatranscriptomic patterning in phototrophic Chloroflexi inhabiting a microbial mat in a geothermal spring. ISME J. doi:10.1038/ismej.2013.52

Klatt, C. G., Wood, J. M., Rusch, D. B., Bateson, M. M., Hamamura, N., Heidelberg, J. F., et al. (2011). Community ecology of hot spring cyanobacterial mats: predominant populations and their functional potential. ISME J. 5, 1262-1278.

Liu, Z., Klatt, C. G., Ludwig, M., Rusch, D. B., Jensen, S. I., Kühl, M., et al. (2012). 'Candidatus Thermochlorobacter aerophilum:' an aerobic chlorophotoheterotrophic member of the phylum Chlorobi defined by metagenomics and metatranscriptomics. ISME J. 6, 1869-1882.

Liu, Z., Klatt, C. G., Wood, J. M., Rusch, D. B., Ludwig, M., Wittekindt, N., et al. (2011). Metatranscriptomic analyses of chlorophototrophs of a hot-spring microbial mat. ISME J. 5, 1279-1290.

Ludwig, W., Strunk, O., Westram, R., Richter, L., Meier, H., Yadhukumar, et al. (2004). ARB: a software environment for sequence data. Nucleic Acids Res. 32, 1363-1371.

Macur, R. E., Langner, H. W., Kocar, B. D., and Inskeep, W. P. (2004). Linking geochemical processes with microbial community analysis: successional dynamics in an arsenicrich, acid-sulfate-chloride geothermal spring. Geobiology 2, 163-177.

Madigan, M. T. (1984). A novel photosynthetic purple bacterium isolated from a Yellowstone hot spring. Science 225, 313-315.

Madigan, M. T., and Brock, T. D. (1975). Photosynthetic sulfide oxidation by Chloroflexus aurantiacus, a filamentous, photosynthetic, gliding bacterium. J. Bacteriol. 122, 782-784.

Madigan, M. T., Jung, D. O., Karr, E. A., Sattley, W. M., Achenbach, L. A., and van der Meer, M. T. J. (2005). “Diversity of anoxygenic phototrophs in contrasting extreme environments," in Geothermal Biology and Geochemsistry in Yellowstone National Park, eds W. P. Inskeep and T. R. McDermott (Bozeman: Montana State University Publications), 203-219.

Madigan, M. T., Petersen, S. R., and Brock, T. D. (1974). Nutritional studies on Chloroflexus, a filamentous photosynthetic, gliding bacterium. Arch. Microbiol. 100, 97-103.

Madigan, M. T., Takigiku, R., Lee, R. G., Gest, H., and Hayes, J. M. (1989). Carbon isotope fractionation by thermophilic phototrophic sulfur bacteria: evidence for autotrophic growth in natural populations. Appl. Environ. Microbiol. 55, 639-644.

Marcia, M., Ermler, U., Peng, G., and Michel, H. (2009). The structure of Aquifex aeolicus sulfide:quinone oxidoreductase, a basis to understand sulfide detoxification and respiration. Proc. Natl. Acad. Sci. U.S.A. 106, 9625-9630.
Markowitz, V. M., Chen, I.-M. A., Chu, K., Szeto, E., Palaniappan, K., Grechkin, Y., et al. (2012). IMG/M: the integrated metagenome data management and comparative analysis system. Nucleic Acids Res. 40, D123-D129.

Mavromatis, K., Ivanova, N., Chen, A., Szeto, E., Markowitz, V., and Kyrpides, N. C. (2009). Standard operating procedure for the annotations of microbial genomes by the production genomic facility of the DOE JGI. Stand. Genomic Sci. 1, 63-67.

McClesky, R. B., Ball, J. A., Nordstrom, D. K., Holloway, J. M., and Taylor H. E. (2005). Water-chemistry Dato for Selected Hot Springs, Geysers, and Streams in Yellowstone Nationa Park, Wyoming, 2001-2002. OpenFile Report 2004-1316. Reston, VA: U.S. Geological Survey.

Melendrez, M. C., Lange, R. K., Cohan, F. M., and Ward, D. M. (2011). Influence of molecular resolution on sequence-based discovery of ecological diversity among Synechococcus populations in an alkaline siliceous hot spring microbial mat. Appl. Environ. Microbiol. 77, 1359-1367.

Miller, J. R., Delcher, A. L., Koren, S., Venter, E., Walenz, B. P., Brownley, A., et al. (2008). Aggressive assembly of pyrosequencing reads with mates. Bioinformatics 24, 2818-2824.

Miller, S. R., Castenholz, R. W., and Pedersen, D. (2007). Phylogeography of the thermophilic cyanobacterium Mastigocladus laminosus. Appl. Environ. Microbiol. 73, 4751-4759.

Miller, S. R., Purugganan, M. D., and Curtis, S. E. (2006). Molecular population genetics and phenotypic diversification of two populations of the thermophilic cyanobacterium Mastigocladus laminosus. Appl. Environ. Microbiol. 72, 2793-2800.

Miller, S. R., Strong, A. L., Jones, K. L., and Ungerer, M. C. (2009). Bar-coded pyrosequencing reveals shared bacterial community properties along the temperature gradients of two alkaline hot springs in Yellowstone National Park. Appl. Environ. Microbiol. 75, 4565-4572.

Nold, S. C., and Ward, D. M. (1996). Photosynthate partitioning and fermentation in hot spring microbial mat communities. Appl. Environ. Microbiol. 62, 4598-4607.

Nübel, U., Bateson, M. M., Vandieken, V., Wieland, A., Kuhl, M., and Ward, D. M. (2002). Microscopic examination of distribution and phenotypic properties of phylogenetically diverse Chloroflexaceae-related bacteria in hot spring microbial mats. Appl. Environ. Microbiol. 68, 4593-4603.

Oksanen, J., Blanchet, F. G., Kindt, R., Legendre, P., Minchin, P. R., O'Hara, R. B., et al. (2012). Vegan: Community Ecology Package. R Package Version 2.0-5. Available at: http://CRAN.Rproject.org/package $=$ vegan

Parks, D. H., and Beiko, R. G. (2010). Identifying biologically relevant differences between metagenomic communities. Bioinformatics 26, 715-721.

Pfennig, N. (1974) Rhodopseudomonas globiformis, sp. n., a new species of the Rhodospirillaceae. Arch. Microbiol. 100, 197-206.

Pierson, B. K., and Castenholz, R. W. (1974). A phototrophic gliding filamentous bacterium of hot springs, Chloroflexus aurantiacus, gen. and sp. nov. Arch. Microbiol. 100, 5-24.

Pierson, B. K., Parenteau, M. N., and Griffin, B. M. (1999). Phototrophs in high-iron-concentration microbial mats: physiological ecology of phototrophs in an iron-depositing hot spring. Appl. Environ. Microbiol. 65, 5474-5483.

R Development Core Team. (2012). $R$ : $A$ Language and Environment for Statistical Computing. $R$ Foundation for Statistical Computing, Vienna. Available at: URL http://www.Rproject.org.

Rappé, M. S., and Giovannoni, S. J. (2003). The uncultured microbial majority. Annu. Rev. Microbiol. 57, 369-394.

Rowe, J. J., Fournier, R. O., and Morey, G. W. (1973). Chemical Analysis of Thermal Waters in Yellowstone National Park, Wyoming, 1960-65. USGS Open File Report. Available at: http://pubs.er.usgs.gov/

Rusch, D. B., Halpern, A. L., Sutton, G., Heidelberg, K. B., Williamson, S., Yooseph, S., et al. (2007). The sorcerer II global ocean sampling expedition: northwest Atlantic through eastern tropical Pacific. PLoS Biol. 5:e77. doi:10.1371/journal.pbio.0050077

Saeed, A. I., Sharov, V., White, J., Li, J., Liang, W., Bhagabati, N., et al. (2003). TM4: a free, open-source system for microarray data management and analysis. BioTechniques 34 , 374-378.

Selengut, J. D., Haft, D. H., Davidsen, T., Ganapathy, A., Gwinn-Giglio, M., Nelson, W. C., et al. (2007). TIGRFAMs and genome properties: tools for the assignment of molecular function and biological process in 
prokaryotic genomes. Nucleic Acids Res. 35, D260-D264.

Shannon, P., Markiel, A., Ozier, O., Baliga, N. S., Wang, J. T., Ramage, D., et al. (2003). Cytoscape: a software environment for integrated models of biomolecular interaction networks. Genome Res. 13, 2498-2504.

Stamatakis, A. (2006). RAxML-VIHPC: maximum likelihood-based phylogenetic analyses with thousands of taxa and mixed models. Bioinformatics 22, 2688-2690.

Strauss, G., and Fuchs, G. (1993). Enzymes of a novel autotrophic $\mathrm{CO}_{2}$ fixation pathway in the phototrophic bacterium Chloroflexus aurantiacus, the 3-hydroxypropionate cycle. Eur. J. Biochem. 215, 633-643.

Taffs, R., Aston, J. E., Brileya, K., Jay, Z., Klatt, C. G., McGlynn, S., et al. (2009). In silico approaches to study mass and energy flows in microbial consortia: a syntrophic case study. BMC Syst. Biol. 3:114. doi:10.1186/1752-0509-3-114

Tang, K.-H., Barry, K., Chertkov, O., Dalin, E., Han, C., Hauser, L., et al. (2011). Complete genome sequence of the filamentous anoxygenic phototrophic bacterium Chloroflexus aurantiacus. BMC Genomics 12:334. doi:10.1186/1471-2164-12334

Teeling, H., Meyerdierks, A., Bauer, M., Amann, R., and Glöckner, F. O. (2004). Application of tetranucleotide frequencies for the assignment of genomic fragments. Environ. Microbiol. 6, 938-947.

Trouwborst, R. E., Johnston, A., Koch, G., Luther, G. W. I. I. I., and Pierson, B. K. (2007). Biogeochemistry of $\mathrm{Fe}(\mathrm{II})$ oxidation in a photosynthetic microbial mat: implications for precambrian Fe(II) oxidation. Geochim. Cosmochim. Acta 71, 4629-4643. van der Meer, M. T., Schouten, S., de Leeuw, J. W., and Ward, D. M. (2000). Autotrophy of green non-sulphur bacteria in hot spring microbial mats: biological explanations for isotopically heavy organic carbon in the geological record. Environ. Microbiol. 2, 428-435.

van der Meer, M. T. J., Klatt, C. G., Wood, J., Bryant, D. A., Bateson, M. M., Lammerts, L., et al. (2010). Cultivation and genomic, nutritional, and lipid biomarker characterization of Roseiflexus strains closely related to predominant in situ populations inhabiting Yellowstone hot spring microbial mats. J. Bacteriol. 192, 3033-3042.

van der Meer, M. T. J., Schouten, S., Bateson, M. M., Nübel, U., Wieland, A., Kuhl, M., et al. (2005). Diel variations in carbon metabolism by green nonsulfur-like bacteria in alkaline siliceous hot spring microbial mats from Yellowstone National Park. Appl. Environ. Microbiol. 71, 3978-3986.

van der Meer, M. T. J., Schouten, S., Sinninghe Damste, J. S., de Leeuw, J. W., and Ward, D. M. (2003). Compound-specific isotopic fractionation patterns suggest different carbon metabolisms among Chloroflexus-like bacteria in hotspring microbial mats. Appl. Environ. Microbiol. 69, 6000-6006.

van Niel, C. B., and Thayer, L. A. (1930). Report on Preliminary Observations on the Microflora in and Near the Hot Springs in Yellowstone National Park and Their Importance for the Geological Formations. YNP Lib File 731.2, Mammoth, WY.

van Ooteghem, S. A., Jones, A., Van Der Lelie, D., Dong, B., and Mahajan, D. (2004). $\mathrm{H}_{2}$ production and carbon utilization by Thermotoga neapolitana under anaerobic and microaerobic growth conditions. Biotechnol. Lett. 26, 1223-1232.

Wang, Q., Garrity, G. M., Tiedje, J. M., and Cole, J. R. (2007). Naive Bayesian classifier for rapid assignment of rRNA sequences into the new bacterial taxonomy. Appl. Environ. Microbiol. 73, 5261-5267.

Ward, D. M., and Castenholz, R. W. (2000). "Cyanobacteria in geothermal habitats," in Ecology of Cyanobacteria, eds B. A. Whitton, and M. Potts (Dordrecht: Kluwer Academic Publishers), 37-59.

Ward, D. M., Castenholz, R. W., and Miller, S. R. (2012). "Cyanobacteria in geothermal habitats," in Ecology of cyanobacteria II. Their diversity in space and time, ed. B. A. Whitton (Heidelberg, GE: Springer), 39-63.

Ward, D. M., Cohan, F. M., Bhaya, D., Heidelberg, J. F., Kühl, M., and Grossman, A. (2008). Genomics, environmental genomics and the issue of microbial species. Heredity 100, 207-219.

Ward, D. M., Ferris, M. J., Nold, S. C., and Bateson, M. M. (1998). A natural view of microbial biodiversity within hot spring cyanobacterial mat communities. Microbiol. Mol. Biol. Rev. 62, 1353-1370.

Ward, D. M., Weller, R., Shiea, J., Castenholz, R. W., and Cohen, Y. (1989). "Hot spring microbial mats: anoxygenic and oxygenic mats of possible evolutionary significance," in Microbial Mats: Physiological Ecology of Benthic Microbial Communities, eds Y. Cohen, and E. Rosenberg (Washington, DC: American Society of Microbiology), 3-15.

Wu, M., and Eisen, J. (2008). A simple, fast, and accurate method of phylogenomic inference. Genome Biol. 9 , R151.
Zarzycki, J., and Fuchs, G. (2011). Coassimilation of organic substrates via the autotrophic 3hydroxypropionate bi-cycle in Chloroflexus aurantiacus. Appl. Environ. Microbiol. 77, 6181-6188.

Zeikus, J. G., and Wolfe, R. S. (1972). Methanobacterium thermoautotrophicus sp. n., an anaerobic, autotrophic, extreme thermophile. J. Bacteriol. 109, 707-713.

Conflict of Interest Statement: The authors declare that the research was conducted in the absence of any commercial or financial relationships that could be construed as a potential conflict of interest.

Received: 01 December 2012; paper pending published: 17 January 2013; accepted: 13 April 2013; published online: 03 June 2013.

Citation: Klatt CG, Inskeep WP, Herrgard MJ, Jay ZJ, Rusch DB, Tringe SG, Parenteau MN, Ward DM, Boomer SM, Bryant DA and Miller SR (2013) Community structure and function of hightemperature chlorophototrophic microbial mats inhabiting diverse geothermal environments. Front. Microbiol. 4:106. doi: 10.3389/fmicb.2013.00106

This article was submitted to Frontiers in Microbial Physiology and Metabolism, a specialty of Frontiers in Microbiology. Copyright (c) 2013 Klatt, Inskeep, Herrgard, Jay, Rusch, Tringe, Parenteau, Ward, Boomer, Bryant and Miller. This is an open-access article distributed under the terms of the Creative Commons Attribution License, which permits use, distribution and reproduction in other forums, provided the original authors and source are credited and subject to any copyright notices concerning any third-party graphics etc. 


\section{APPENDIX}

Table A1 | Community diversity estimated from $16 \mathrm{~S}$ sequence libraries.

\begin{tabular}{|c|c|c|c|c|c|c|c|c|c|c|c|c|}
\hline Site_N umber & $\mathbf{N}$ & 99\% OTUs & Singletons & ACE & Chao1 & SD & $95 U$ & 95D & alpha & SD & Shannon & Simpson \\
\hline BLVA_20 & 364 & 130 & 102 & 773.9 & 873.1 & 318.3 & 1791.1 & 462.5 & 72.3 & 6.0 & 3.8 & 14.1 \\
\hline Chocolate Pots_7 & 380 & 127 & 100 & 402 & 421.1 & 94.0 & 669.1 & 286.6 & 66.9 & 5.4 & 3.4 & 9.2 \\
\hline Mushroom Spring_15 (Bacteria) & 314 & 112 & 66 & 214.1 & 220.9 & 37.7 & 322.5 & 168.3 & 62.3 & 5.6 & 4.1 & 37.5 \\
\hline Mushroom Spring_15 (Archaea) & 265 & 35 & 16 & 65 & 77.7 & 33.2 & 199.5 & 46.1 & 10.8 & 1.1 & 2.7 & 8.9 \\
\hline
\end{tabular}

Richness indexes ACE, Chao1 (w/95\% confidence intervals) and diversity indexes (Fisher's alpha, Shannon-Weaver, and Simpson's Index).

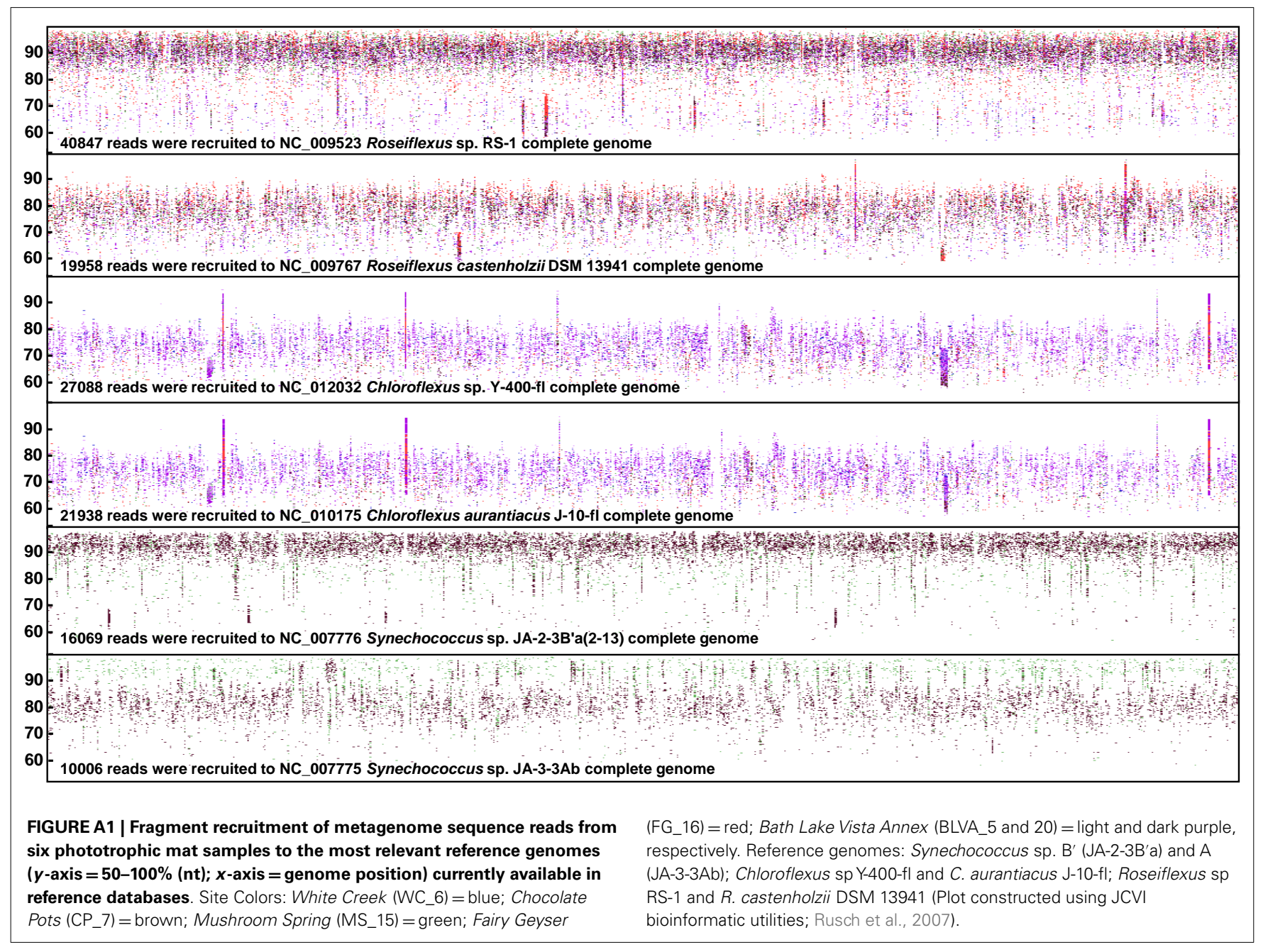



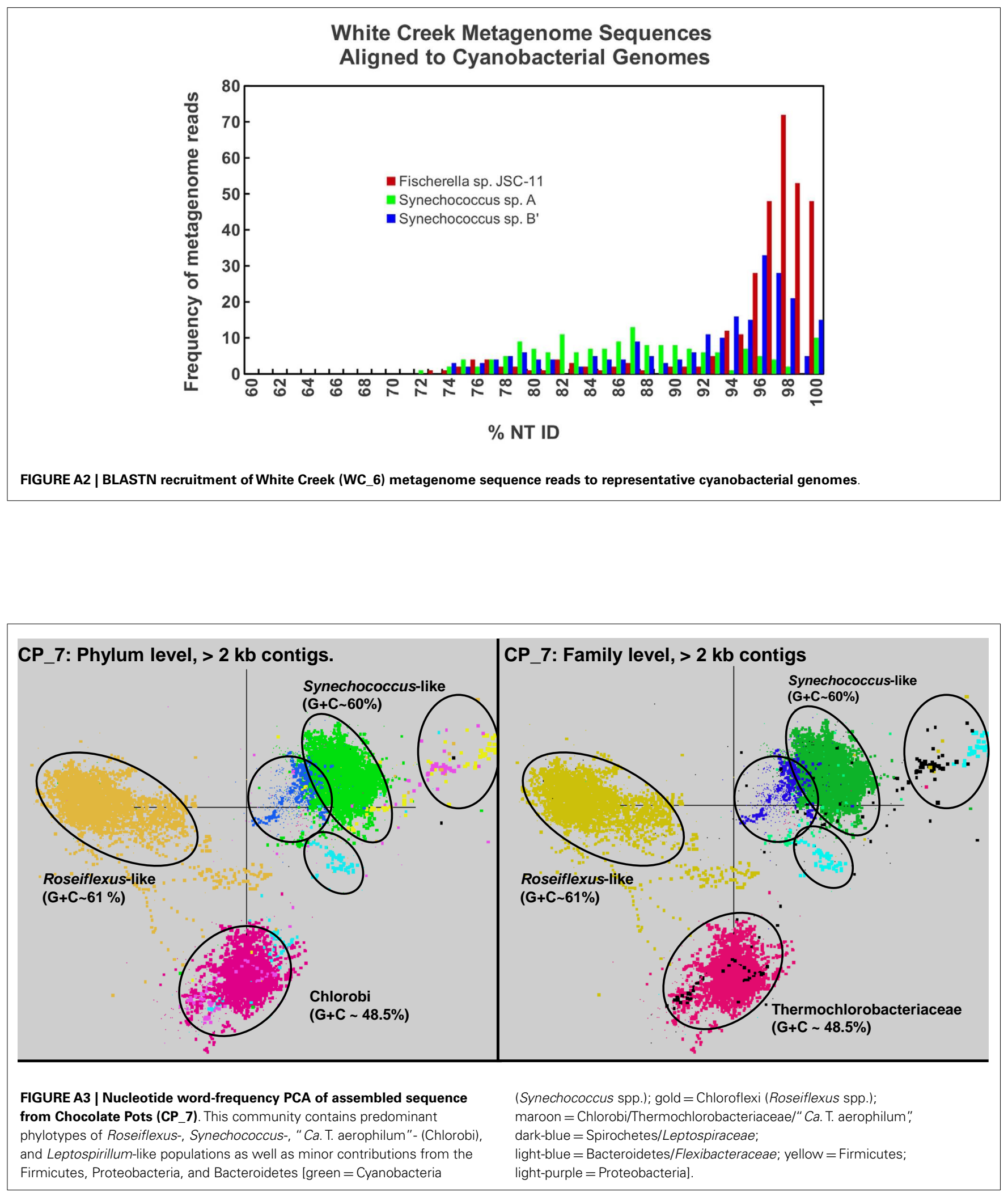

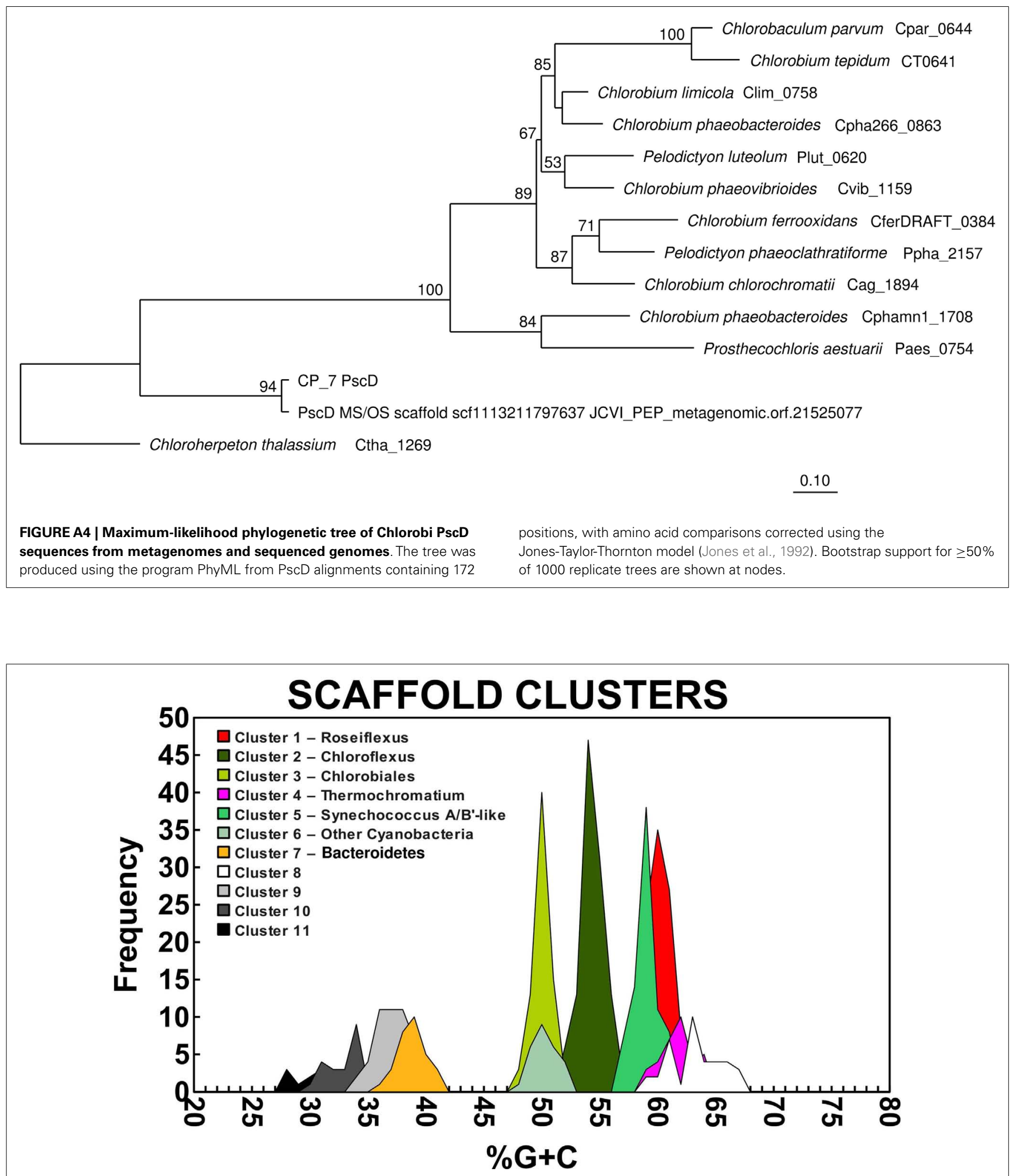

FIGURE A5 | G + C Composition of Scaffold Clusters. Scaffold clusters greater than $10 \mathrm{kbp}$ were demarcated using oligonucleotide frequencies as depicted in Figure 4. 


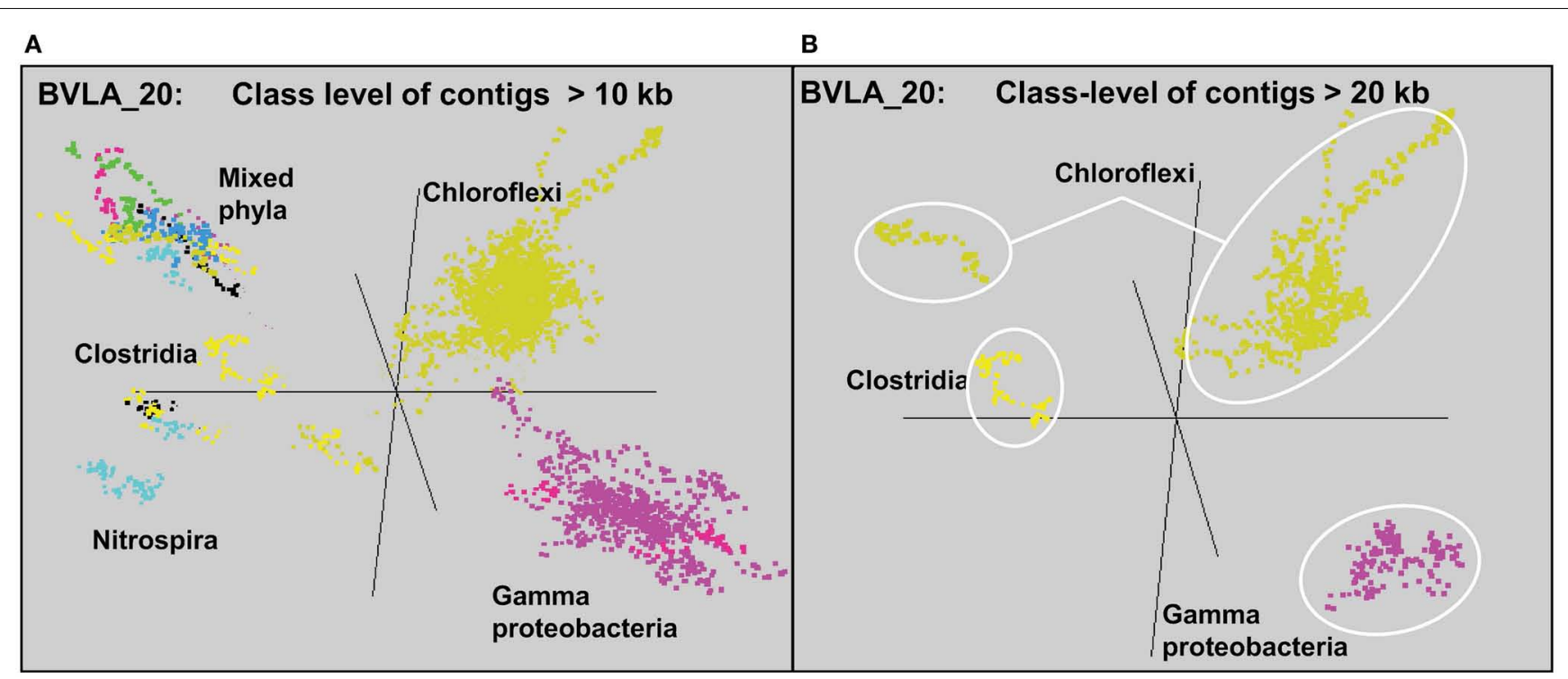

FIGURE A6 | Predominant metagenome sequence assemblies [(A) $>\mathbf{1 0} \mathrm{kb}$ contigs and $(B)>\mathbf{2 0} \mathrm{kb}$ contigs only] from Bath Lake Vista Annex (BLVA_20) sampled during a bloom of purple-sulfur bacteria (Gamma-proteobacteria). Major clusters are identified at the class-level (purple= Gamma-proteobacteria; gold = class Chloroflexi; yellow = Clostridia, light-blue = Nitrospira; green $=$ Acidobacteria; maroon = Betaproteobacteria; dark-blue $=$ Deltaproteobacteria). 
A

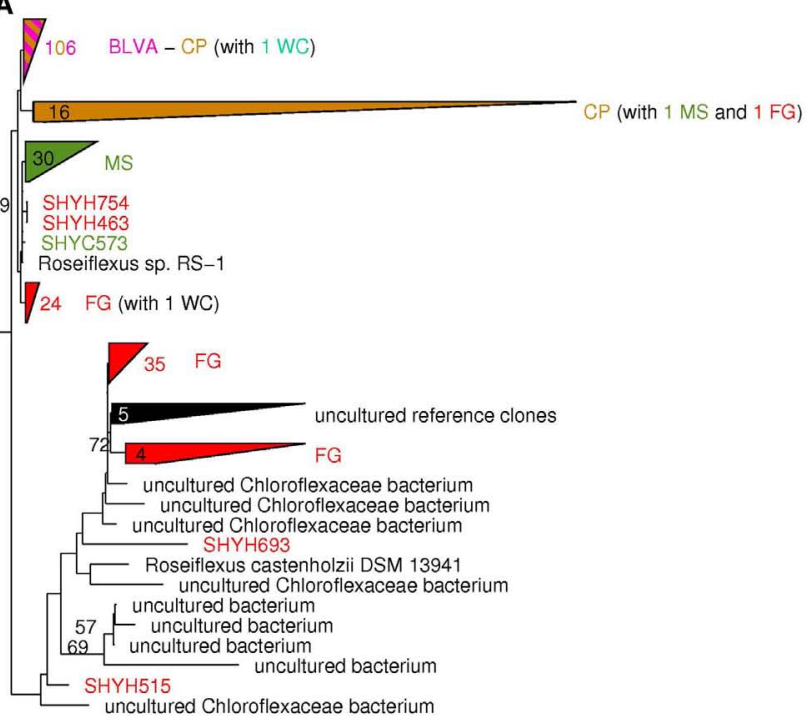

0.10

Bath Lake Vista Annex

$\square$ white Creek

$\square$ Chocolate Pots

$\square$ Mushroom Spring

Fairy Geyser

FIGURE A7 | Neighbor-joining phylogenetic tree of Chloroflexi 16S rRNA sequences from all clone libraries. (A) Sub-branch of tree corresponding to Roseiflexus spp. (B) Sub-branch of tree corresponding to FAPs related to Chloroflexus spp. and other organisms capable of producing
B

$\int_{116}$ BLVA

SHIH533

4 sulfidic hot spring bacterium NPE

SIAO411
SHYC578

W WC - BLVA

73 4 2 wo

4 SHHA633

2 WG

BLVAgreen

SHYC759

$7243 \mathrm{MS}$

प 19 wo

86 $\mathrm{SHYC605}$

Chloroflexus sp. 396-1

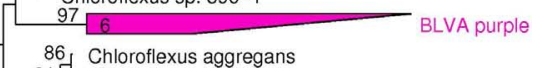

$91[-$ Chloroflexus aggregans

$69-\begin{gathered}\text { Chloroflexus aggregans } \\ \text { uncultured bacterium }\end{gathered}$

56. Chloroflexus aurantiacus

uncultured bacterium

67 Chloroflexus aurantiacus $\mathrm{J}-10-\mathrm{fl}$

100 Chloroflexus sp. Y-400-

90 Chloroflexus aurantiacus

BLVA purple

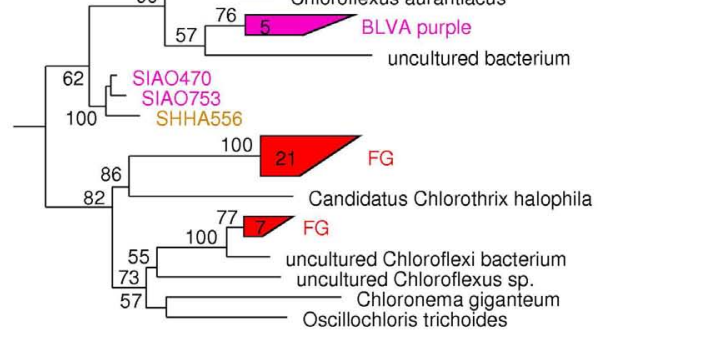

bacteriochlorophyll c. Sequences are color coded according to spring origin, and numbers adjacent to polygons indicate the number of clones in each clade. Bootstrap support for $\geq 50 \%$ of 1000 replicate trees are shown at nodes. 


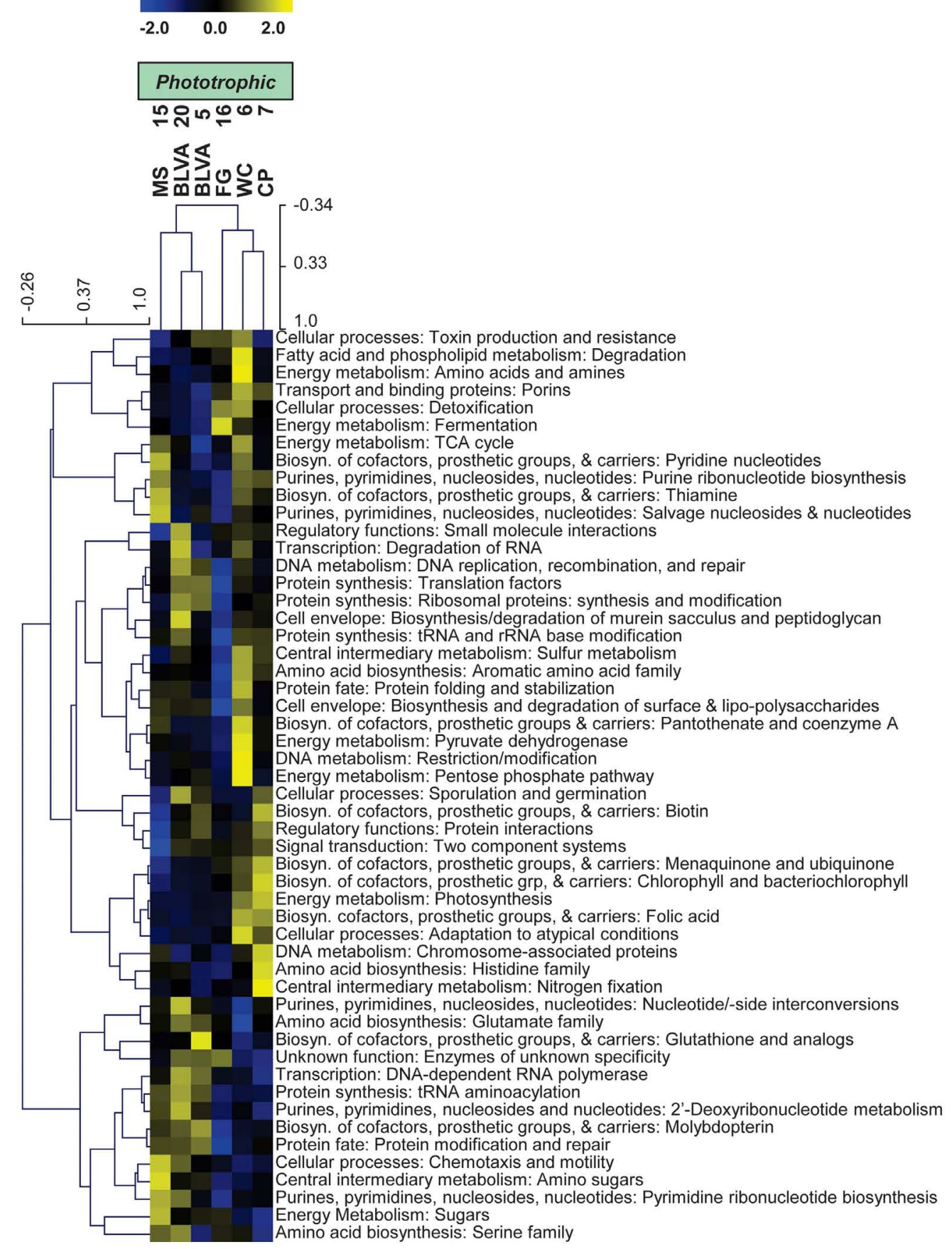

FIGURE A8 | Hierarchical cluster analysis of relative abundances of genes in all TIGRFAMs grouped into functional categories. Data were standardized by functional category before clustering to avoid biasing analysis by a few categories with high gene abundance. Pearson correlation was used as the distance measure for average linkage agglomerative clustering. 